\title{
أثر الغطاء الغيمي في درجات الحرارة في العراق
}

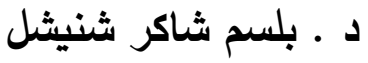

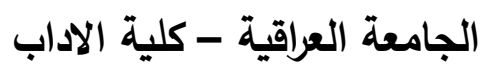

\section{Dr.BalsamSH85@gmail.com}

(مُلَخَّصُ الَبَحث)

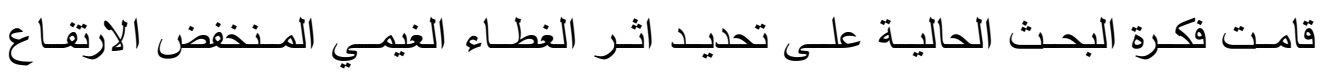

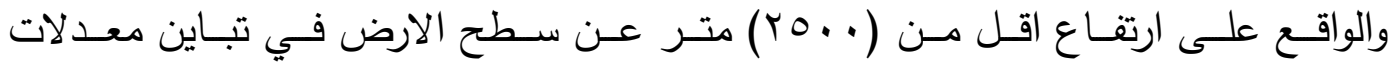

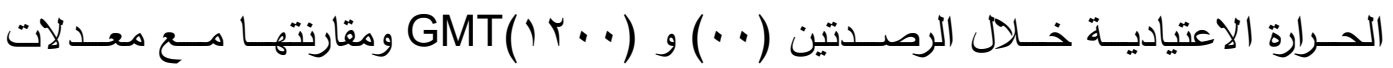

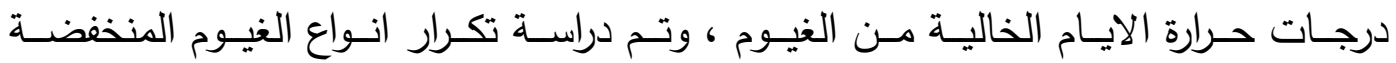

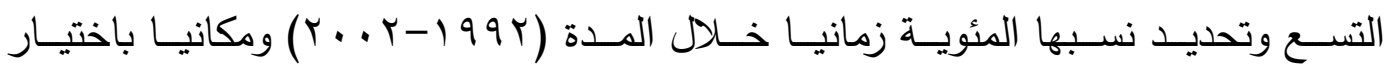

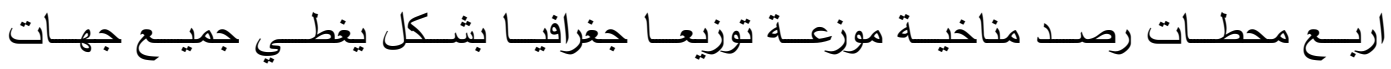

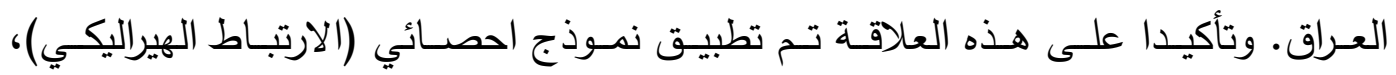

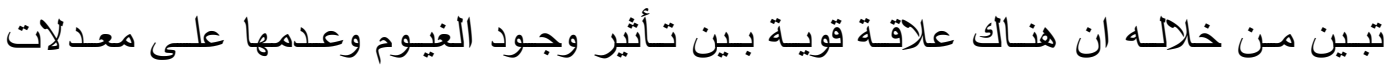

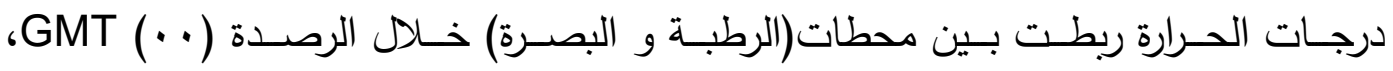

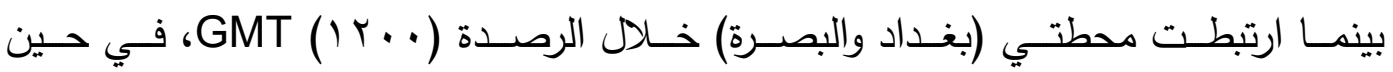

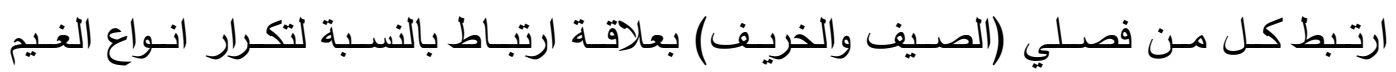

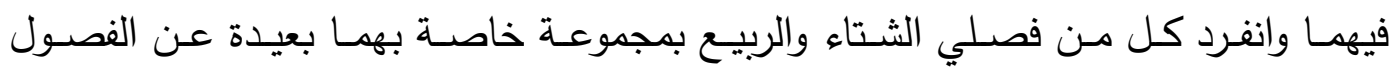
الاخرى في كل من رصدتي الليل والنهار.

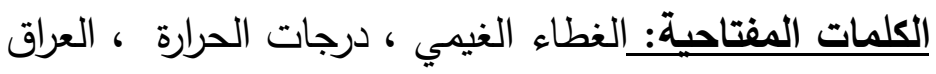
المقدمة:

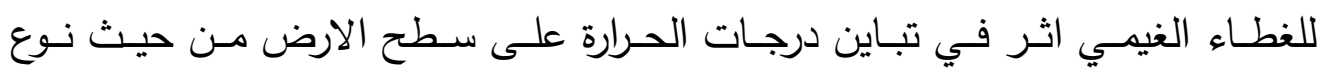

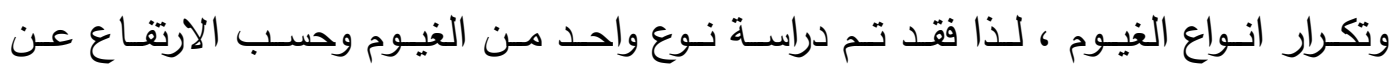

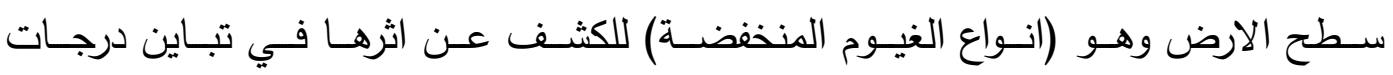

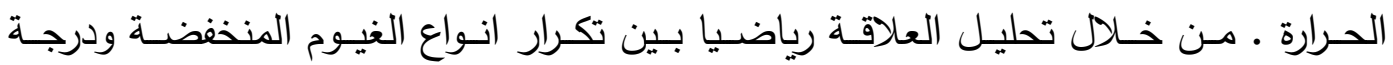

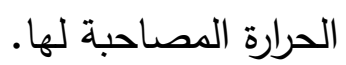
مـن الجدير بالـكر ان اختيـار موضـوع البحث (أثر الغطـاء الغيمسي في درجـات

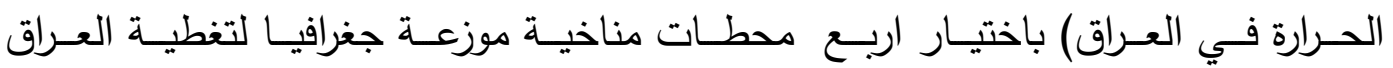

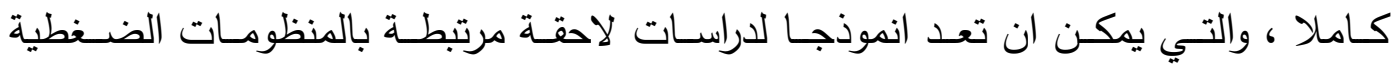

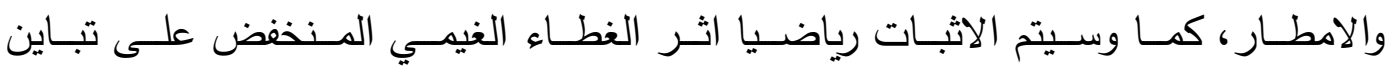
درجات الحرارة في الدحطات المختارة . 
يعـد الاتـر للغطـاء الغيمسي على درجـات الحـرارة ذا بعـد متبـاين، ومــن الدراسـة الحاليـة يـتم قيـاس العلاقـات بـين تكـرار الغيـوم مـن جهـة، ودرجـات الحــرارة الاعتياديـة

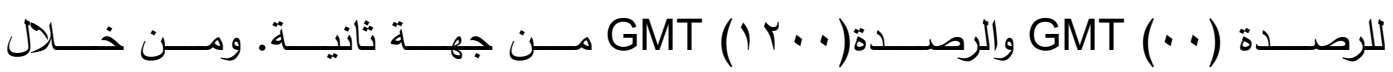
مؤشرات رياضية يتبين مدى قوة العلاقة وتصنيفها . مثكلة البحث: مونري ردئ

تتمحور مشكلة البحث في محاولة الاجابة عن الاسئلة الاتية : I ـ ماهي انواع الغيوم المنخفضة المؤثرة في العراق، وايهما اكثر تكرارا؟

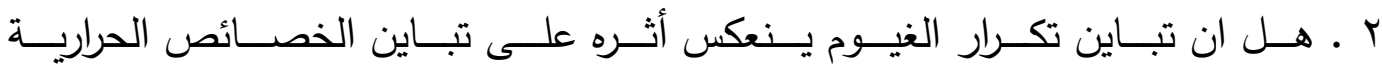
المصاحبة لها ؟ فرضية البحث: I ـ هنالك تباين في تكرار انواع الغيوم المؤثرة على العراق •

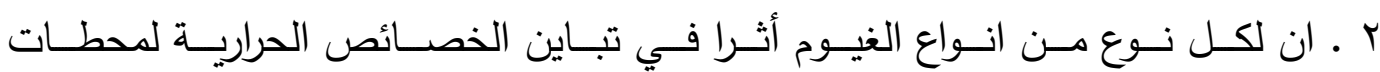
منطقة الدراسة . ب ـ هنـاك علاقـة احصــائية مــا بـين الغطـاء الغيمسي ونوعـهـ وتبـاين معـدلات درجـات الحرارة المسجلة في المحطات المدروسة .

\section{حدود البحث:}

تتحصـر الحـدود المكانيـة للبحـث بالحـدود السياسـية للعـراق، وفلكيـا مـا بـين قوسـي

طـــــول(

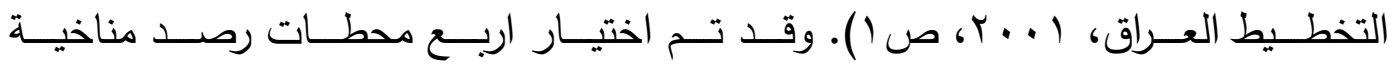
رئيسـية هـي (الموصـل، الرطبـة، بغــداد، البصــرة) كونهـا تمثـل تبـاين ســحح العـراق

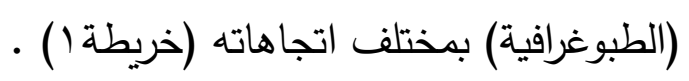

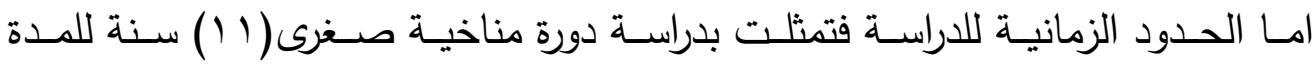

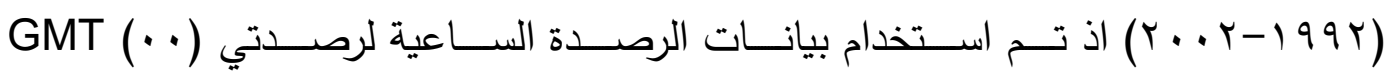

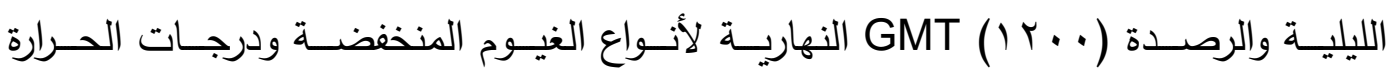
المصاحبة لها وللرصدات نفسها . وقـد اعتمـد المـنهج التحليلي واسـتخدام اسـلوب التحليـل الكمي لتوضـيح العلاقـة مـا ببـين تبـاين انـواع الغيـوم وتبـاين درجـات الحـرارة فـي العـراق ، ومـن ثـم تمثيـل النتـائج بشكل انموذج رياضي وخرائطي يحدد العلاقة ما بين انواع الغيوم ودرجات الحرارة . 


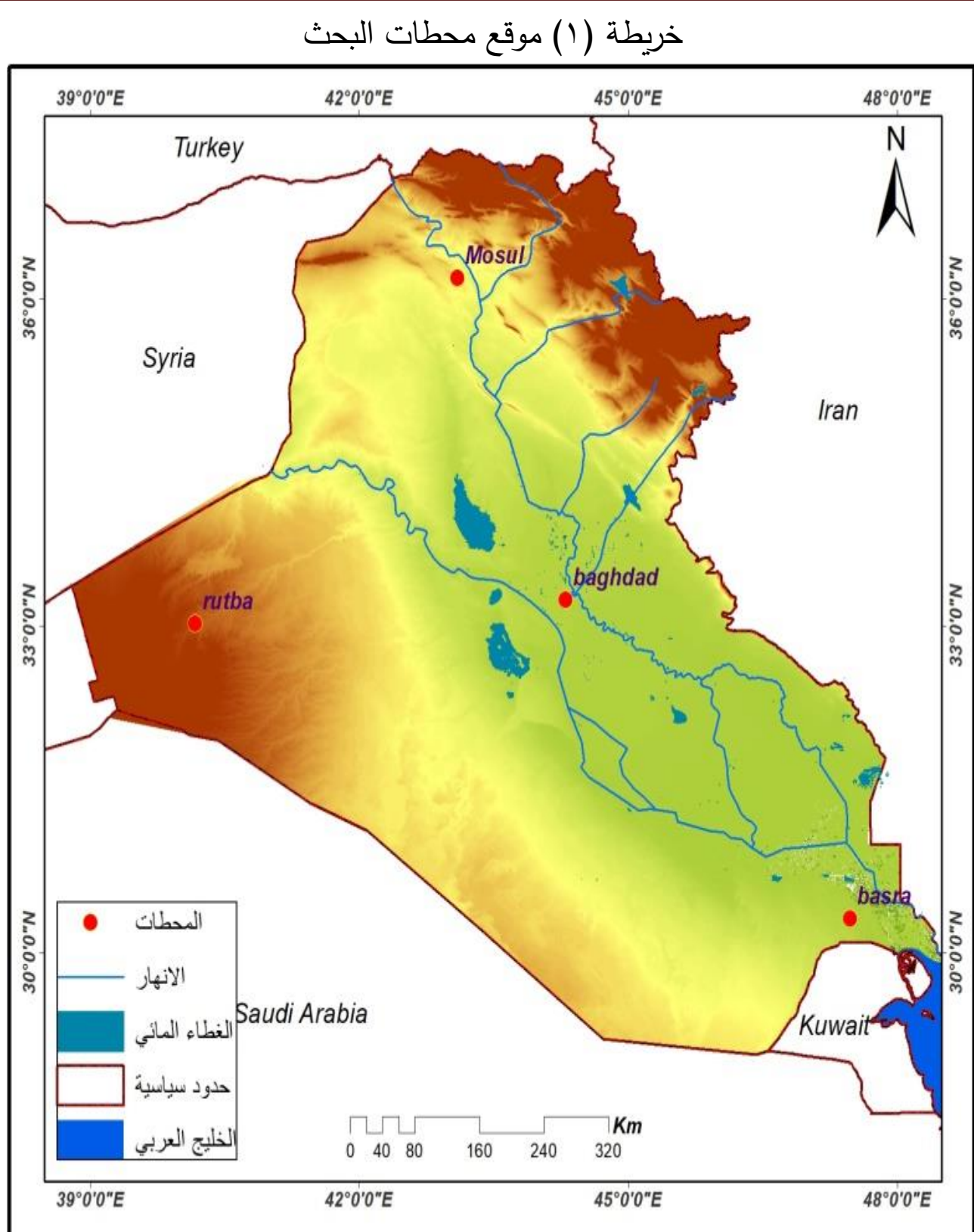

المحور الاول : اليات العقل :

تطلب البحث بعض الاجراءات للقيام بالدراسة الحالية ومنها :

توفر البيانـات ومعالجتها ونتائجها التي تمحورت بجداول رقميـة ومخططسات بيانيـة

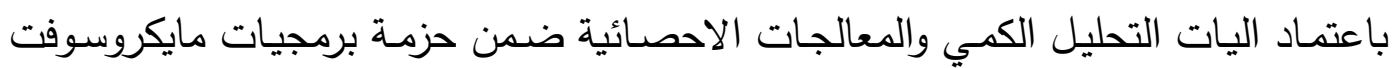
امتداد Excel والمختص بالمعالجات الاحصائية اصدار • • ب وبرنامج

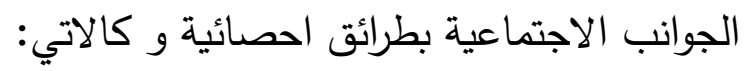
ا 1 ( مصادر البيانات :

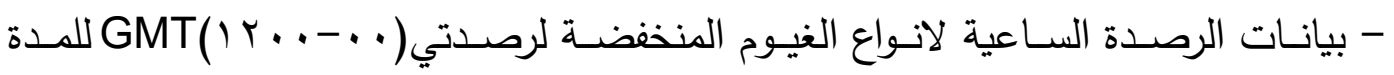
. $(r+r-199 r)$

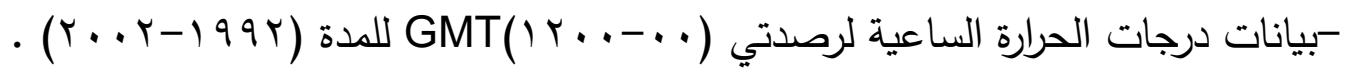


- ادخال البيانات ببرنامج Excel (v.2010) ومعالجتها ببناء جداول مثلت ( تكرار الغيوم

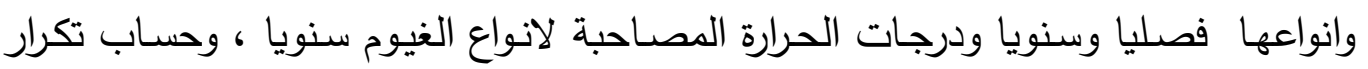

$$
\text { ومعدلات حرارة ايام التغييم وعدم التغييم). }
$$

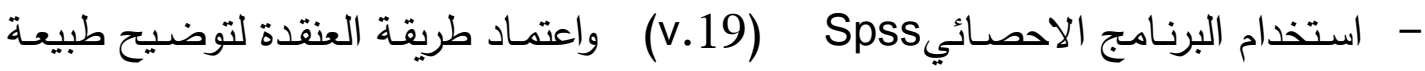
العلاقات التصنيفية بين انواع الغيوم ودرجة حرارتها .

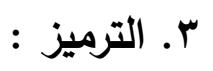

جدول (1) يبين انواع الغيوم ودلالاتها وخصائصها .

\begin{tabular}{|c|c|c|}
\hline خصائصها & 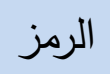 & 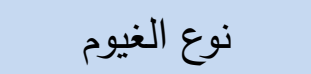 \\
\hline طقس حسن ،بيضاء اللون مبعثرة ،قليلة التغطية & $\mathrm{Cu}_{1}$ & ركام بسيط \\
\hline 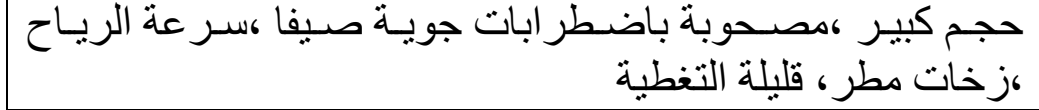 & $\mathrm{Cu}_{2}$ & ركام متوسط \\
\hline يظهر بسمك كبير ، بلارة والية التغطيام العاصفة ،بلور ات جليديـة ،يصـاحبها & $\mathrm{Cb}_{3}$ & ركام مزني \\
\hline 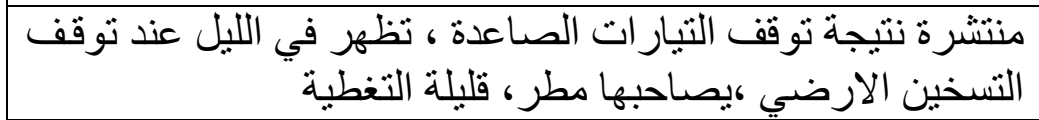 & $\mathrm{Sc}_{4}$ & ركام طبقي متفلطح \\
\hline 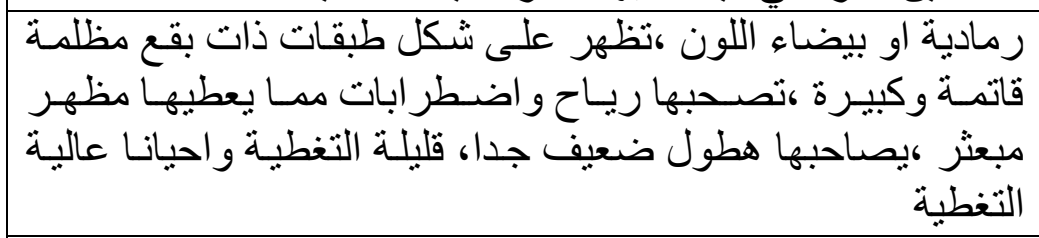 & $\mathrm{Sc}_{5}$ & نانشئ عن تفلئح غير \\
\hline 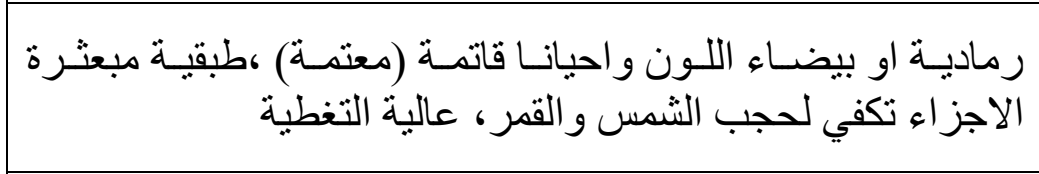 & $\mathrm{St}_{6}$ & مصاحبة للجو \\
\hline 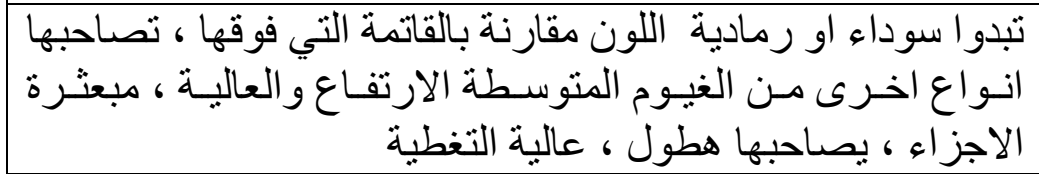 & $\mathrm{Fs}_{7}$ & مصاحبة للجو \\
\hline 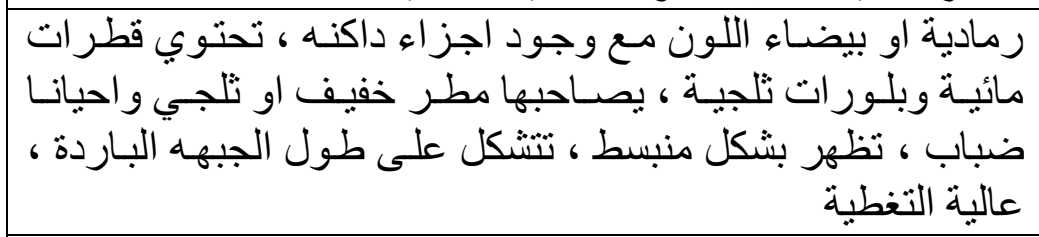 & $\mathrm{Sc}_{8}$ & 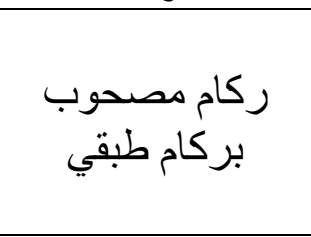 \\
\hline 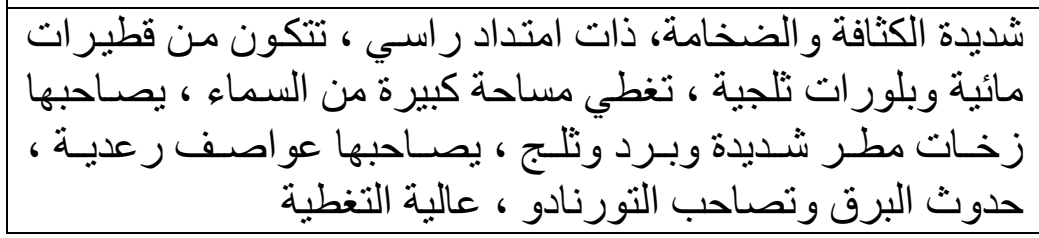 & $\mathrm{Cb}_{9}$ & 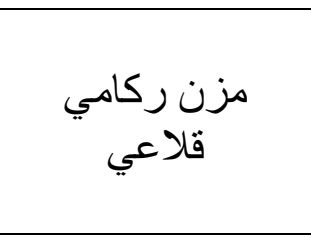 \\
\hline
\end{tabular}


المحور الثاني : تكرلات انواع الغيوم المنخفضة :

ـ تكرار ايام التغييم في منطقة الدراسة :

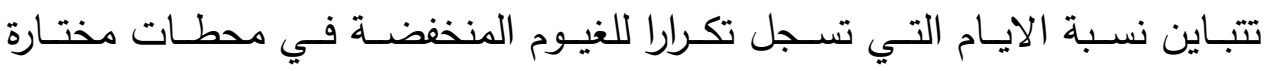

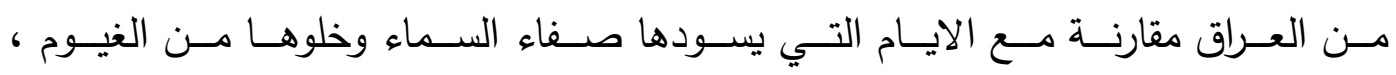

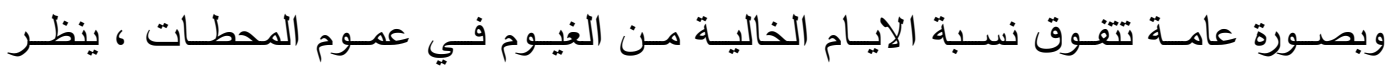

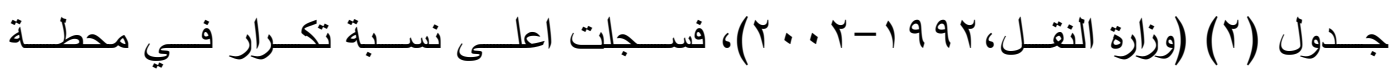

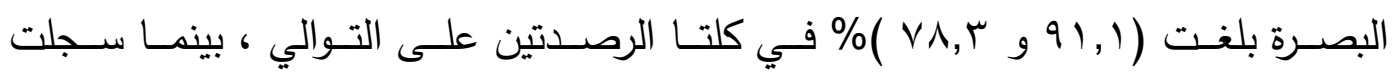

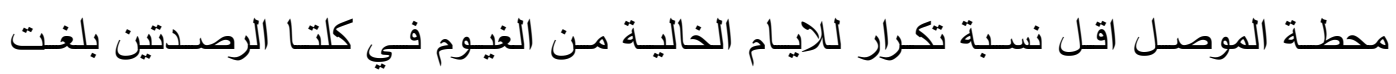

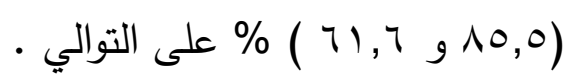

جدول (r) المجموع الكلي والنسبة المئوية لأيام التغييم و و عدمها في محطات منطقة البحث للمدة

$(r \cdot r-199 r)$

\begin{tabular}{|c|c|c|c|c|c|c|c|c|c|}
\hline \multicolumn{2}{|c|}{ البصره } & \multicolumn{2}{|c|}{ بغداد } & \multicolumn{2}{|c|}{ الرطبة } & \multicolumn{2}{|c|}{ الموصل } & \multirow{2}{*}{\multicolumn{2}{|c|}{ الرصدة الرحطات }} \\
\hline$\%$ & مجموع & $\%$ & مجموع & $\%$ & مجموع & $\%$ & مجموع & & \\
\hline 91.1 & 2659 & 90.2 & 3622 & 89.1 & 3580 & 85.5 & 3447 & 00 & الايام \\
\hline 78.3 & 3146 & 75.7 & 3042 & 68.9 & 2768 & 61.6 & 2466 & . 12 & غلي \\
\hline 8.9 & 358 & 9.8 & 395 & 10.9 & 437 & 14.2 & 570 & 00 & ايام \\
\hline 21.7 & 871 & 34.3 & 975 & 31.1 & 1249 & 38.4 & 1541 & $\cdots 12$ & التغييم \\
\hline
\end{tabular}

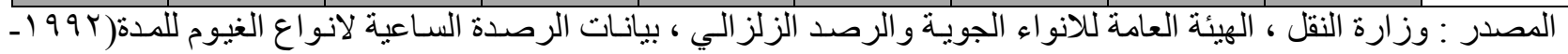

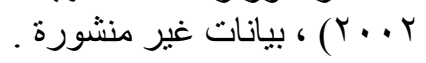

في حين سجلت المحطة نفسها اعلى نسبة لأيام التغييم بين المحطات المدروسة بلغت

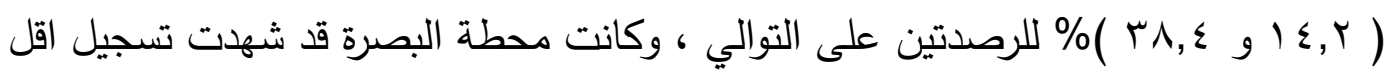

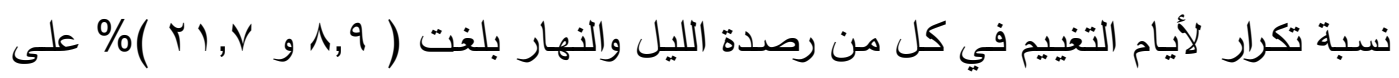

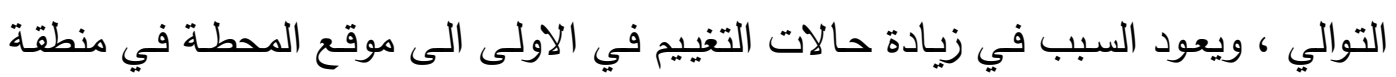

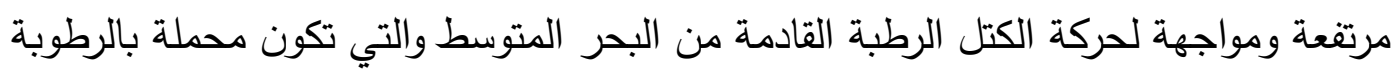

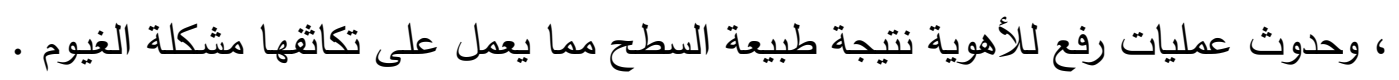

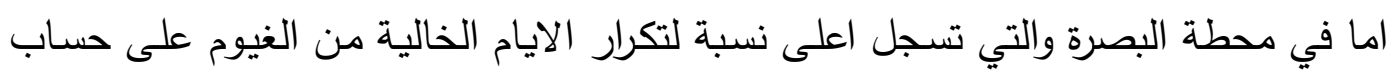

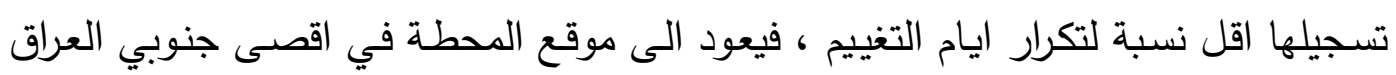

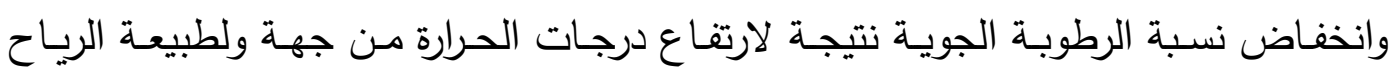

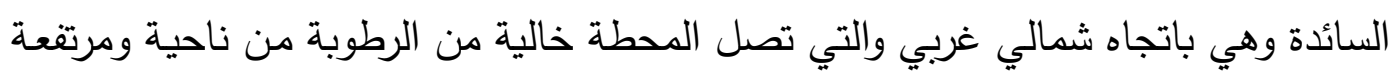
الحرارة من جهة اخرى مما لا يسمح بتشكل الغيوم . 
ويظهر من الشكل (A-1 ) ان هناك علاقة ارتباط جمعت ما بين مجموع الايام الخالية من الغيوم في محطات بغداد والبصرة والرطبة بمجموعة واحدة خلال رصدة الليل بينما انفردت محطة الموصل بمجموعتها خلال نفس الرصدة لتسجيلها اقل عدد لايام الخالية

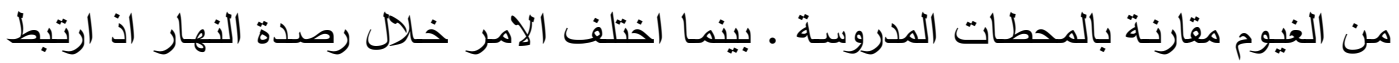
كل من محطتي البصرة وبغداد بمجموعة واحدة ومحطتي الموصل والرطبة بمجموعة ثانية.

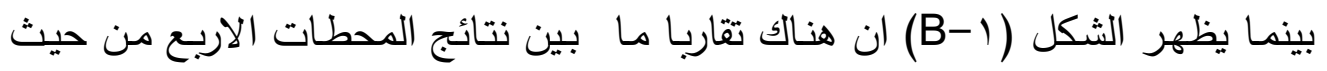

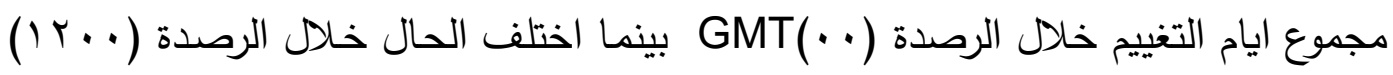

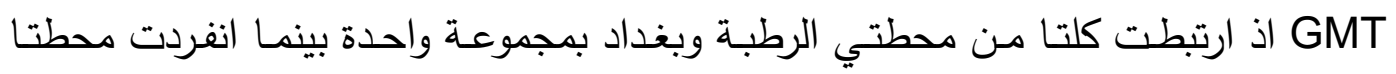

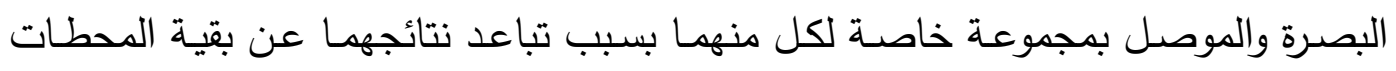
وخلال الرصدة نغسها .

شكل (1) المجاميع الارتباطية (العنقدة ) لمجموع ايام التغييم وعدم التغييم في المحطات المدروسة

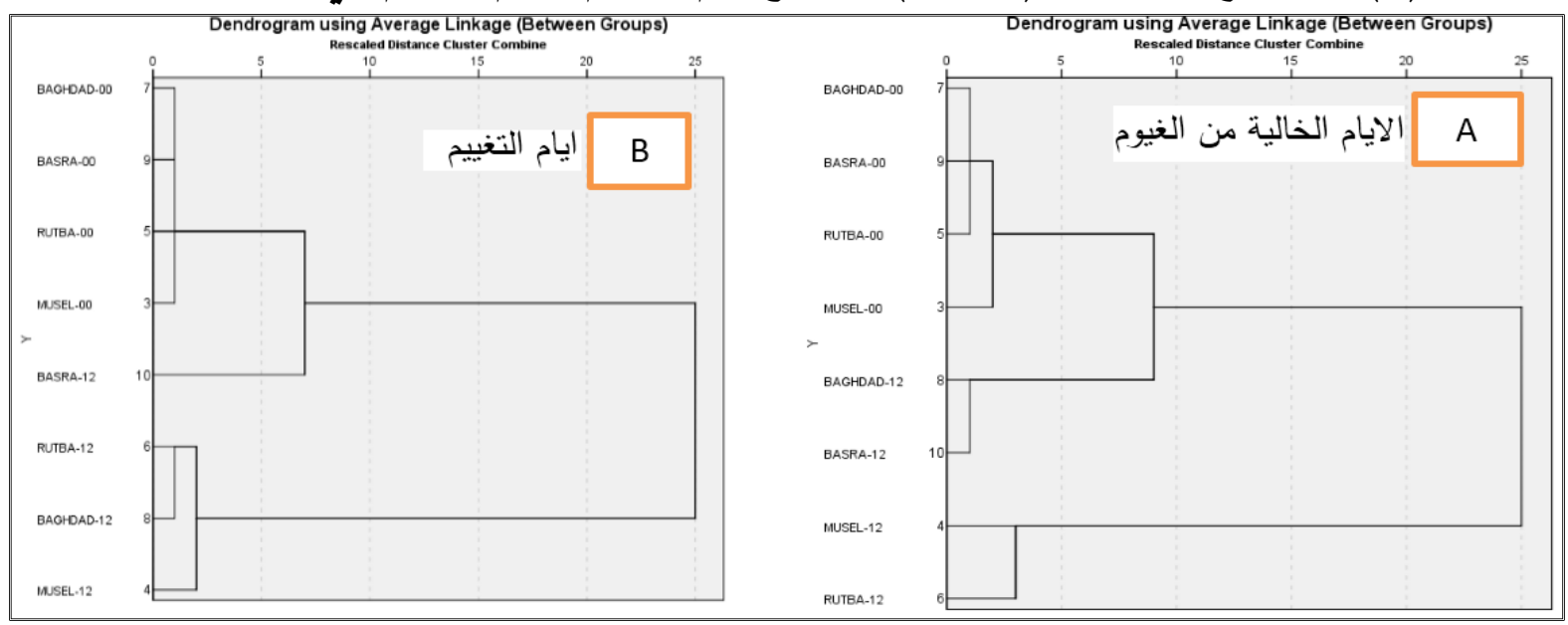

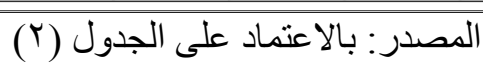

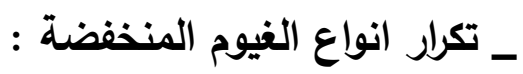

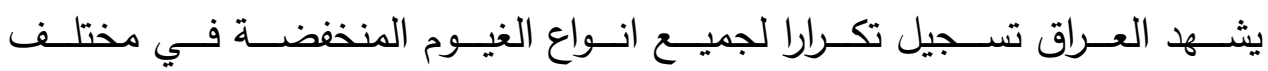

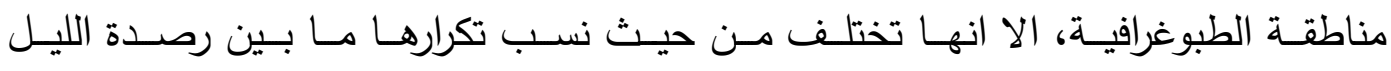

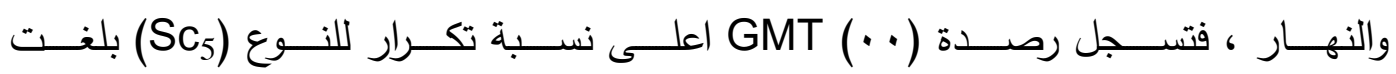

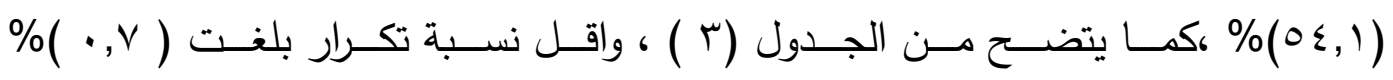

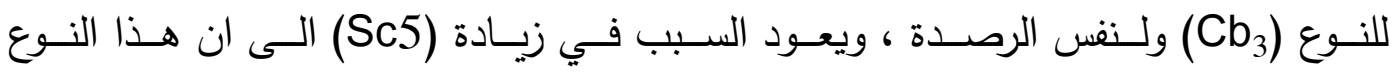

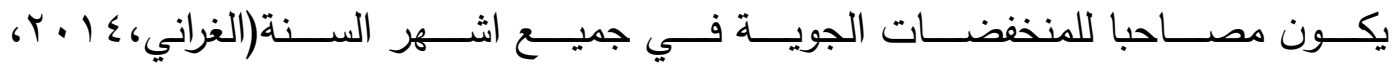

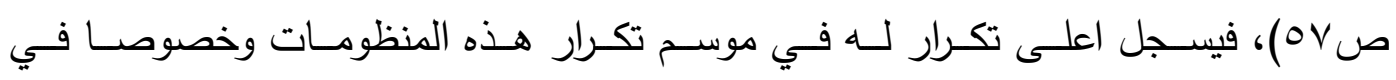

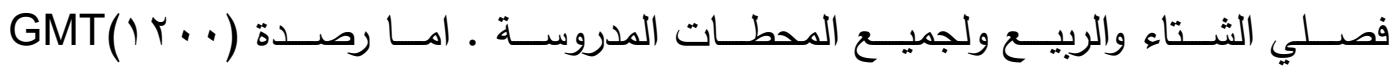

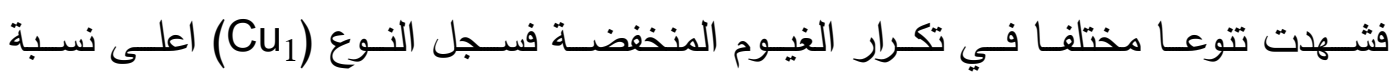

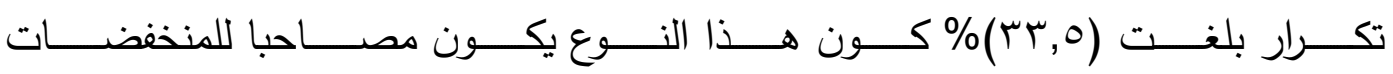




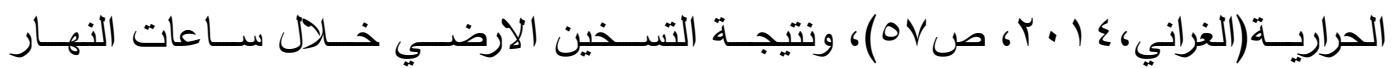

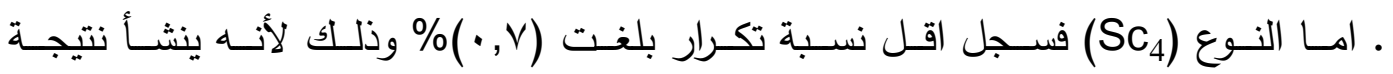

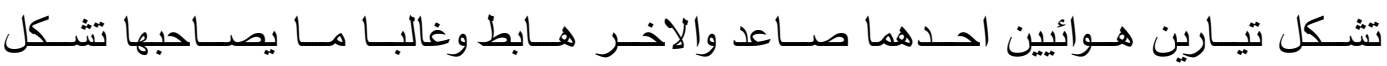

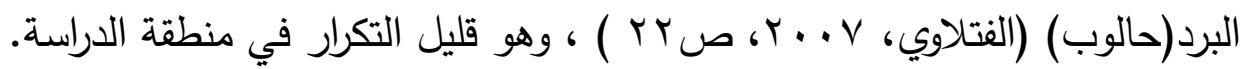

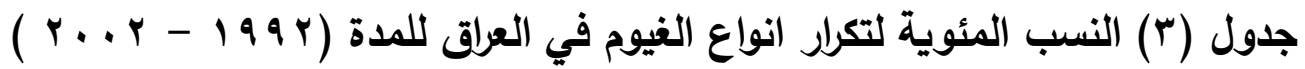

\begin{tabular}{|c|c|c|c|c|c|c|c|c|c|}
\hline \%Cb9 & $\%$ Sc8 & $\% F s 7$ & \%St6 & $\% S c 5$ & $\%$ Sc4 & $\% \mathrm{Cb} 3$ & $\% \mathrm{Cu} 2$ & $\% \mathrm{Cu} 1$ & / الرصدة / \\
\hline 5.8 & 18.4 & 1.8 & 3.6 & 54.1 & 1.1 & 0.7 & 4.7 & 9.8 & 00 \\
\hline 4.5 & 21.5 & 1.5 & 1.3 & 16.8 & 0.7 & 1.8 & 18.4 & 33.5 & . 12 \\
\hline
\end{tabular}

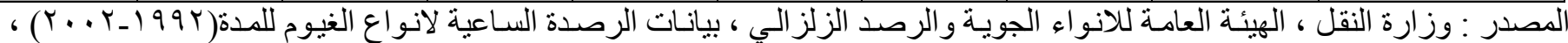

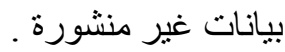

ويظهر من خلال الشكل (A-Y) ان هناك علاقة تربط بين نسب تكرار انواع الغيوم بمجموعة واحدة لانخفاض نسب ( $\mathrm{Cu}_{1}, \mathrm{St}_{6}, \mathrm{Cb}_{9}, \mathrm{Cu}_{2}, \mathrm{Fs}_{7}, \mathrm{Sc}_{4}, \mathrm{Cb}_{3}$ ) تكرارها ، بينما انفرد كل من النوعين (Sc ${ }^{2}$ ) بمجموعة خاصة لكل منهما وذللك

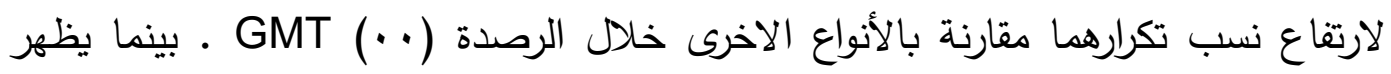

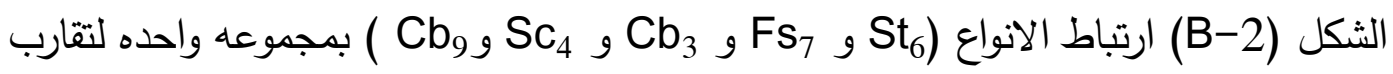

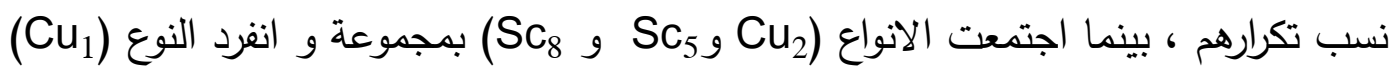

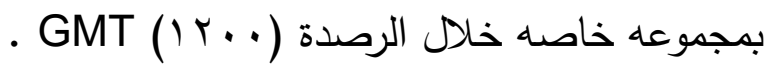

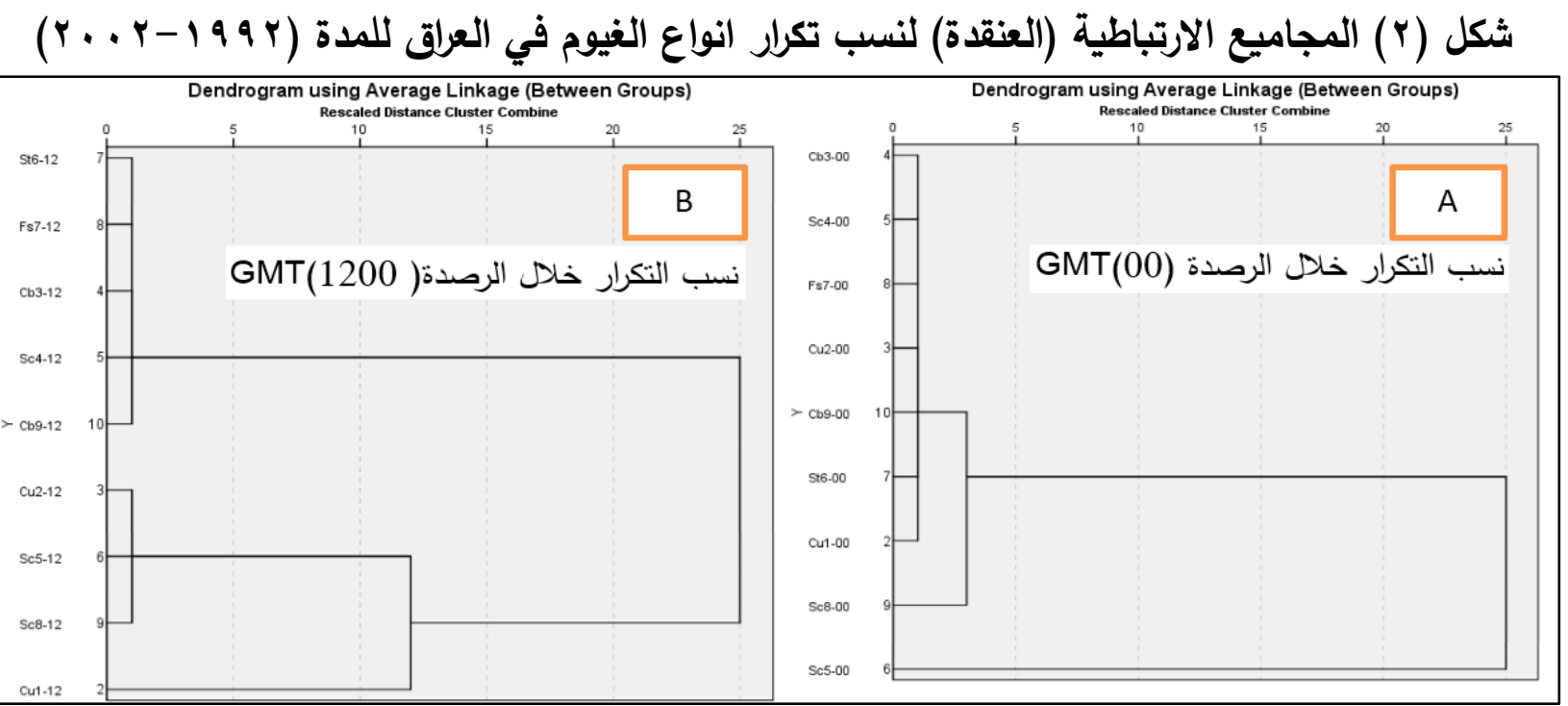

المصدر: بالاعتماد على الجدول (3) (ل) 
_ التكرار الفصلي لأنواع الغيوم :

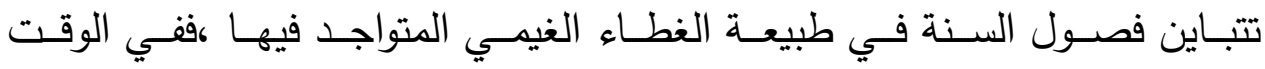

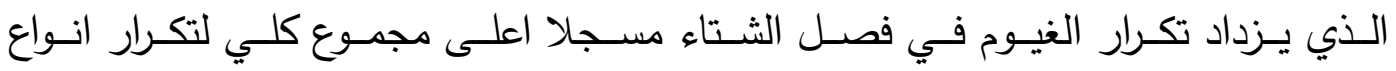

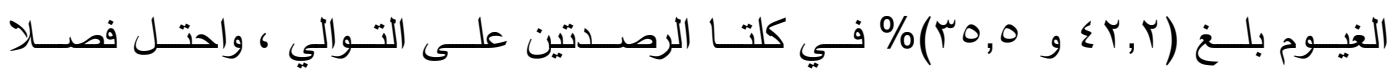

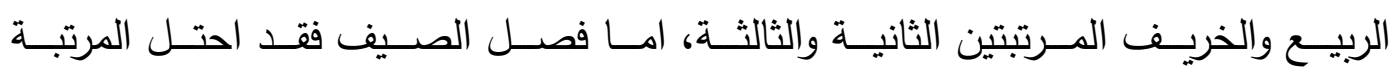

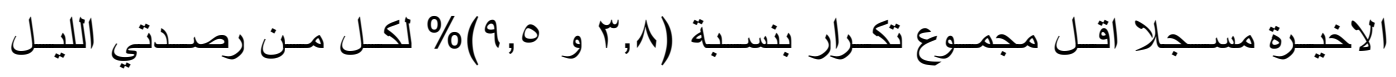

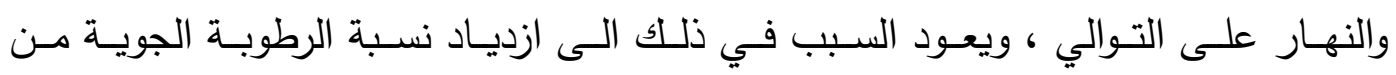

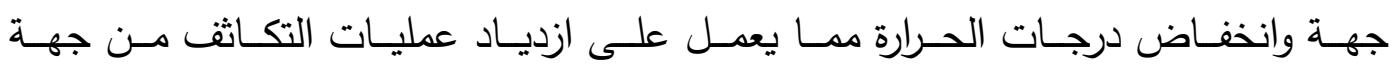

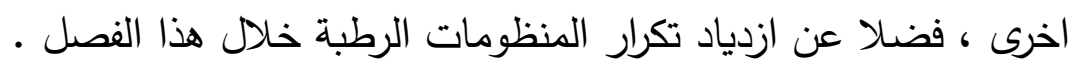

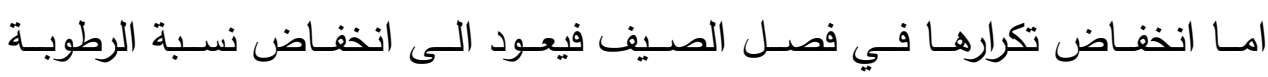

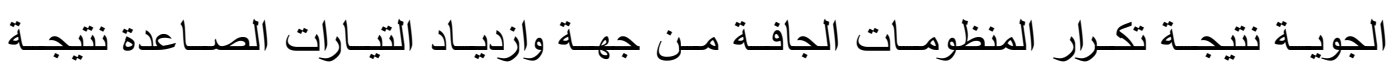
التسخين الارضي من جهة اخرى مما لا يسمح بتشكل الغطاء الغيمي صيفا .

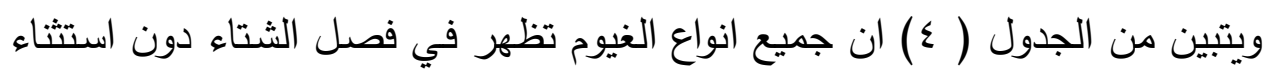

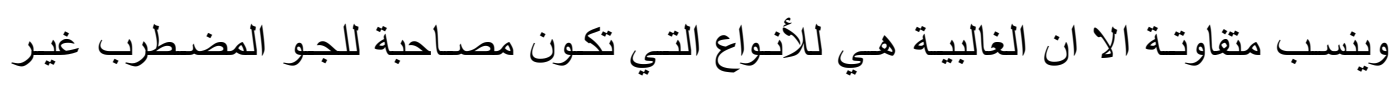

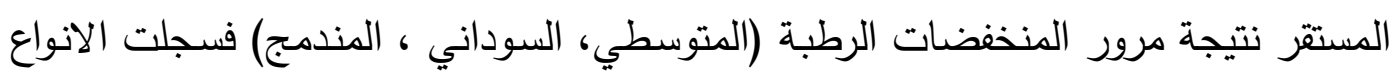

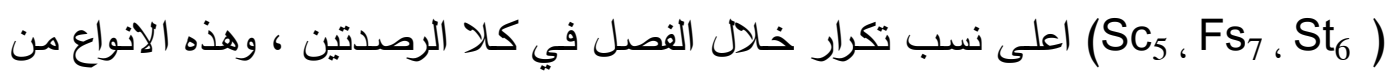

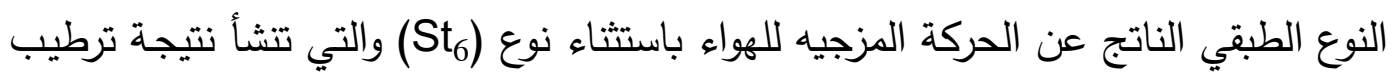

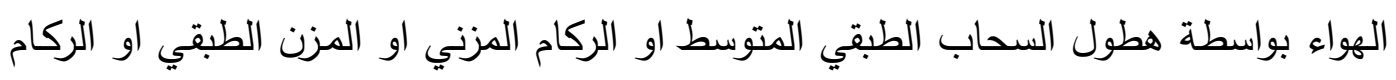

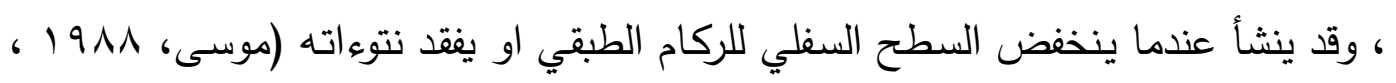

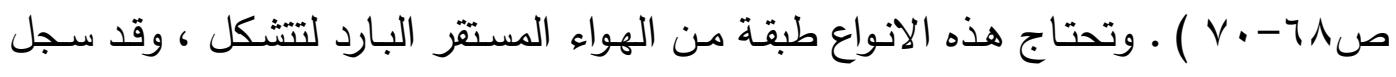

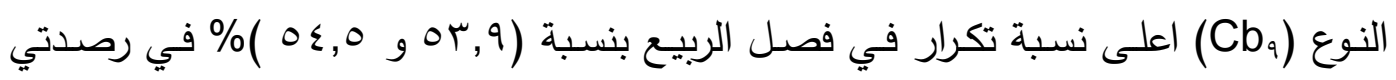

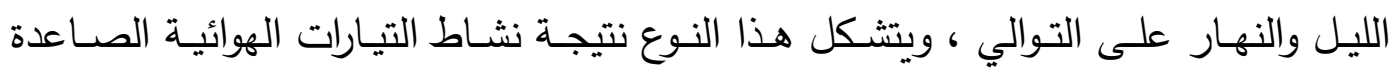
والمضطربة نتيجة مرور المنخفضات الجوية وعمليات التسخين الارضي التي تبدأ بالتزايد

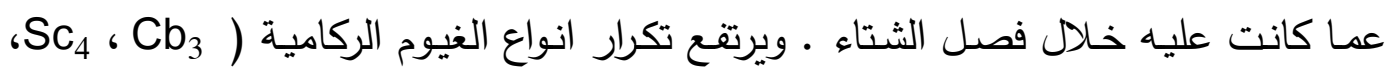
( Cت Cu ، Cu

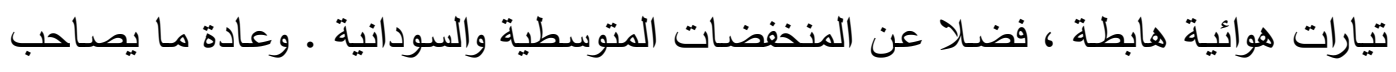

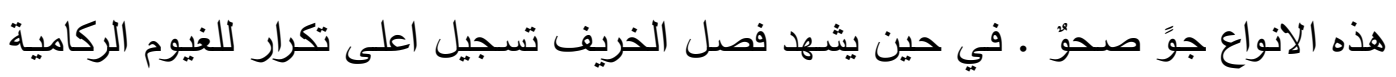
انواع ( ل

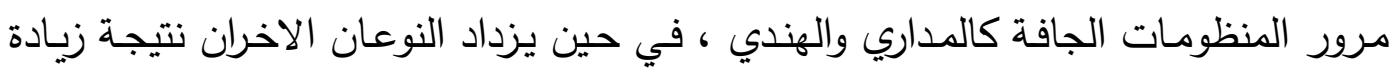
تكرار المنظمات الرطبة خلال هذا الفصل وغالبا ما يصاحبها تساقط مطري . 
جدول ( ) النسب المئوية للتكرار الفصلي لانواع الغيوم في المحطات المدروسة للمدة $(r+r-199 r)$

\begin{tabular}{|c|c|c|c|c|c|c|c|c|}
\hline \multicolumn{2}{|c|}{ الخريف } & \multicolumn{2}{|c|}{ الصيف } & \multicolumn{2}{|c|}{ الربيع } & \multicolumn{2}{|c|}{ الثتاء } & نوع الغيوم \\
\hline$\cdots 12$ & 00 & $\cdots 12$ & 00 & $\cdots 12$ & $\begin{array}{lll}0 & 0\end{array}$ & $\cdots 12$ & 00 & $\begin{array}{l}\text { الرصدة } \\
\text { GMT }\end{array}$ \\
\hline 19.4 & 31.2 & 18.8 & 15.6 & 36.4 & 33.5 & 25.4 & 19.7 & $\mathrm{Cu}_{1}$ \\
\hline 20.5 & 25.3 & 9.6 & 9.6 & 37.2 & 38.6 & 32.7 & 26.5 & $\mathrm{Cu}_{2}$ \\
\hline 31.8 & 25 & 4.7 & 8.3 & 37.6 & 50 & 25.9 & 16.7 & $\mathrm{Cb}_{3}$ \\
\hline 23.5 & 5.3 & 14.7 & 21.1 & 32.4 & 47.3 & 29.4 & 26.3 & $\mathrm{Sc}_{4}$ \\
\hline 16.9 & 15.8 & 2.4 & 1.8 & 32.8 & 34 & 47.8 & 48.4 & $\mathrm{Sc}_{5}$ \\
\hline 8.3 & 12.7 & 1.7 & 0 & 6.7 & 6.4 & 83.3 & 80.9 & $\mathrm{St}_{6}$ \\
\hline 13 & 18.8 & 0 & 0 & 15.9 & 12.5 & 71 & 68.7 & $\mathrm{Fs}_{7}$ \\
\hline 24.3 & 27.2 & 2.8 & 1.9 & 30.8 & 30.8 & 42.1 & 40.1 & $\mathrm{Sc}_{8}$ \\
\hline 18.2 & 26.5 & 4.3 & 2.9 & 54.5 & 53.9 & 23 & 16.7 & $\mathrm{Cb}_{9}$ \\
\hline 20.2 & 20.4 & 9.5 & 3.8 & 34.8 & 33.6 & 35.5 & 42.2 & اللفصئ النسبة \\
\hline
\end{tabular}

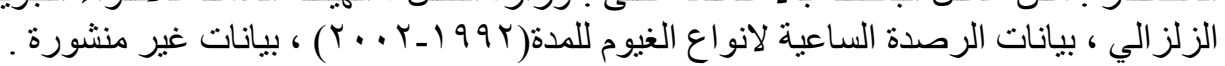

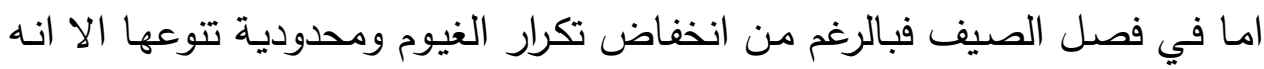

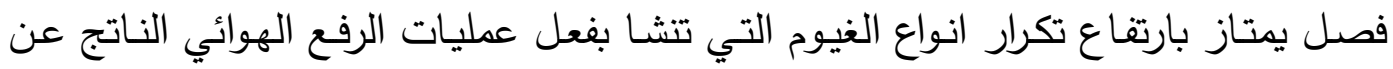

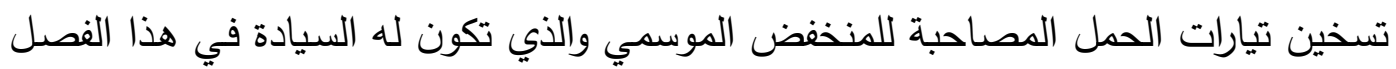

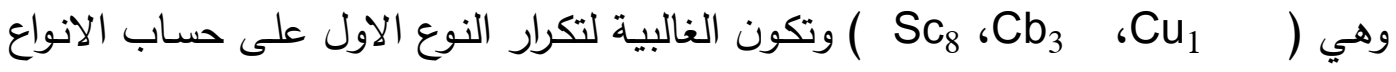

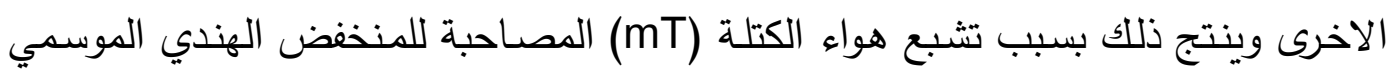

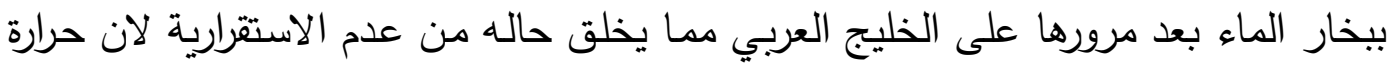

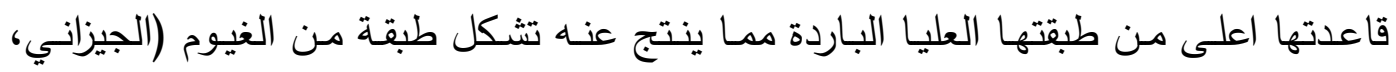
10 بسبب تعدق المنخفض الموسمي ومصاحبة المرتفع المداري العلوي في المستوى ( . (0) هكتوباسكال مما لا يسمح بتثكل هذه الانواع والتي تحتاج الى مستوى تكثيف عالِ وهواء صاعد مستقر لذا فالتيارات الدافئة الهابطة للمرتفع العلوي تعيق تشكل هذا النوع من الغيوم . 
ويظهر من الشكل (r-A) ارتباط فصلي الصيف والخريف بمجموعة واحدة لتقارب

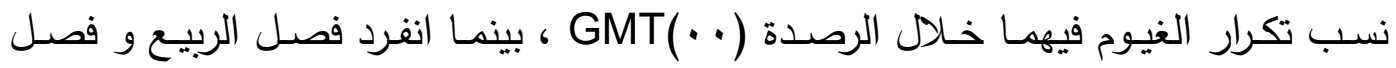

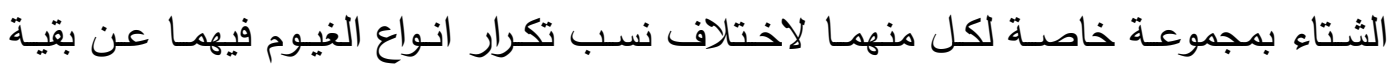

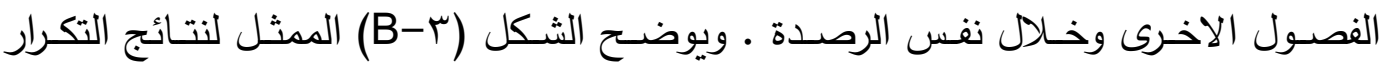

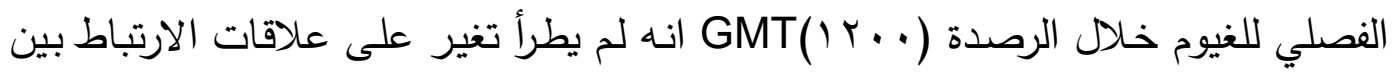

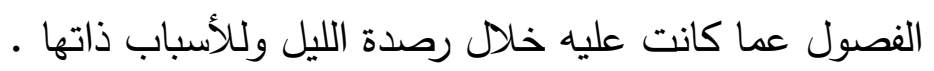

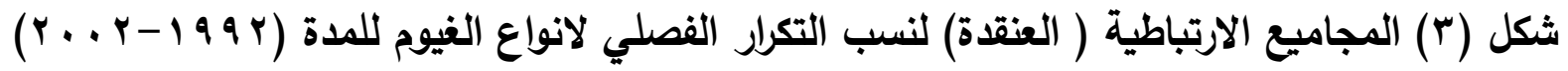

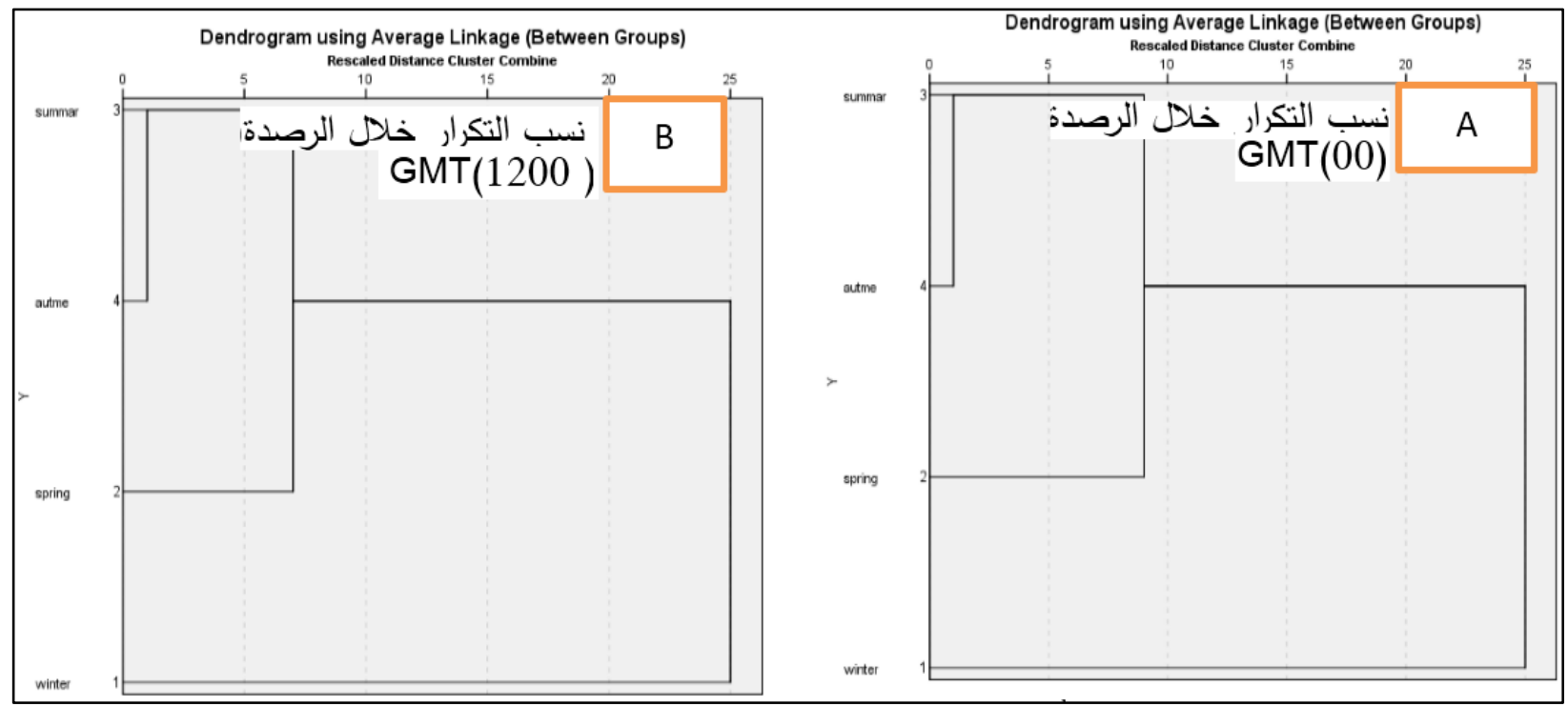

المصدر: الجدول (4) (4)

المحور الثالث: معدلات الحراة السنوية المصاحبة لأنواع الغيوم:

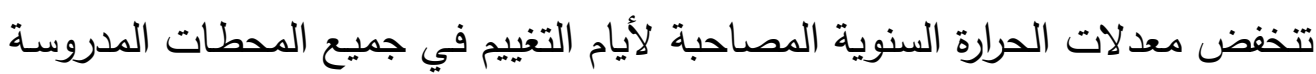

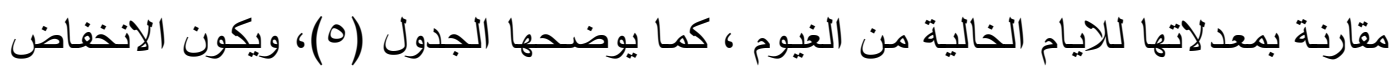

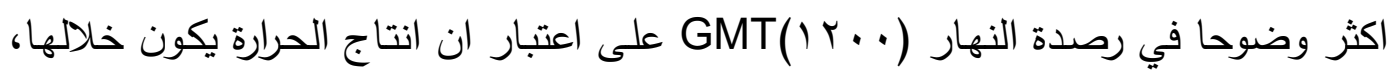
اما رصدة الليل ( · GMT فمن الطبيعي ان تنخفض درجات الحرارة نتيجة لتوقف الانتاج

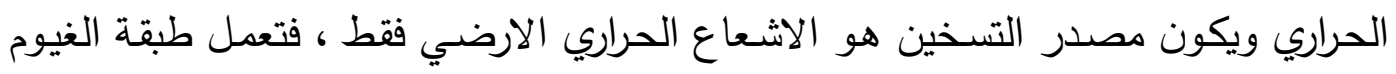

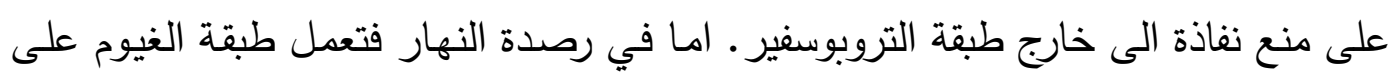

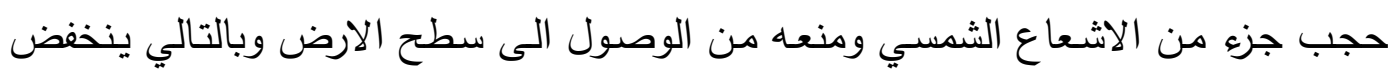

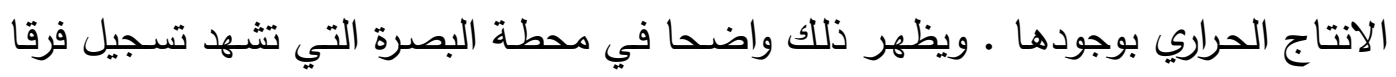

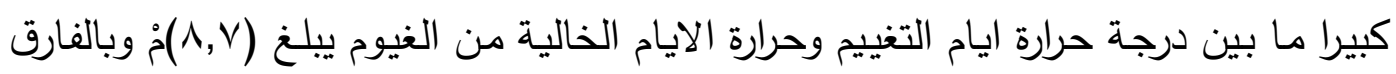

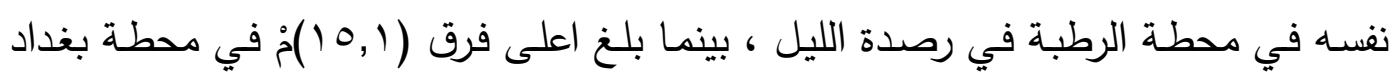

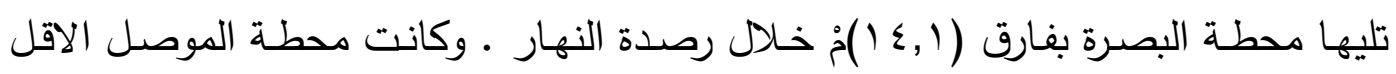


فرقا في درجات الحرارة ويعود السبب الى طبيعة سطحها وارتفاعه من جهة وزيادة تكرار ايام التغييم فيها مما يعمل على خفض درجات الحرارة فيها. جدول (0) معدل الحرارة السنوي لأيام التغييم وعدمها في المحطات منطقة البحث للمدة

\begin{tabular}{|c|c|c|c|c|c|}
\hline & & (r & .1 & & \\
\hline \multirow{2}{*}{ البصرة } & \multirow{2}{*}{ بغداد } & \multirow{2}{*}{ الرطبة } & \multirow{2}{*}{ الموصل } & \multicolumn{2}{|c|}{ المحطات } \\
\hline & & & & \multicolumn{2}{|c|}{ الرصدة GMT } \\
\hline 21.4 & 17.2 & 15.5 & 14.7 & 00 & \multirow{2}{*}{ الايام بدون غيم } \\
\hline 33.3 & 30.9 & 26.8 & 28.1 & 1200 & \\
\hline 12.7 & 11.3 & 6.8 & 11.2 & 00 & \multirow{2}{*}{ ايام التغييم } \\
\hline 18.9 & 15.8 & 15.4 & 18.6 & 1200 & \\
\hline 8.7 & 5.9 & 8.7 & 3.5 & 00 & \multirow{2}{*}{ فرق الحرارة } \\
\hline 14.4 & 15.1 & 11.4 & 9.5 & 1200 & \\
\hline
\end{tabular}

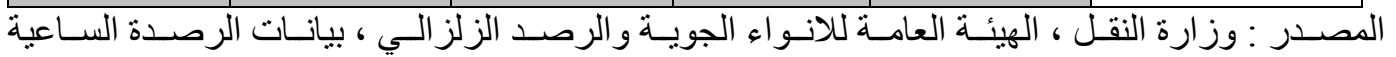

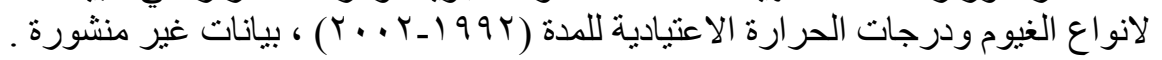

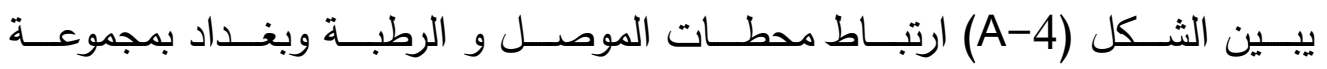

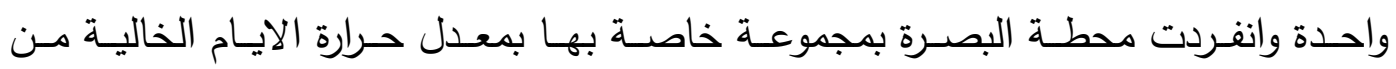

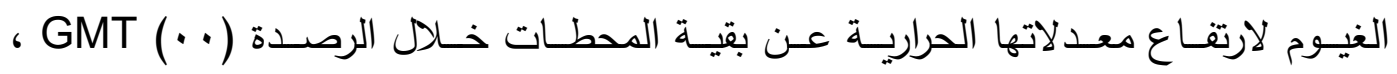

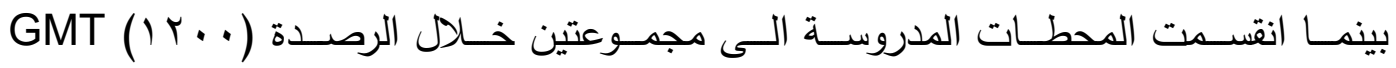

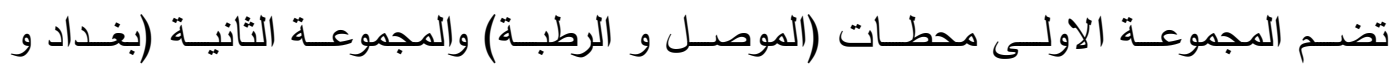

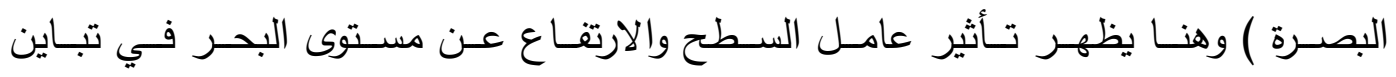

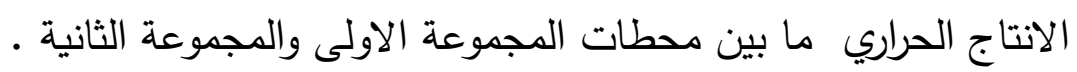

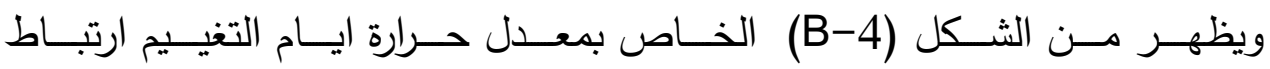

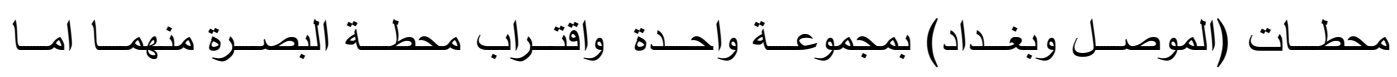

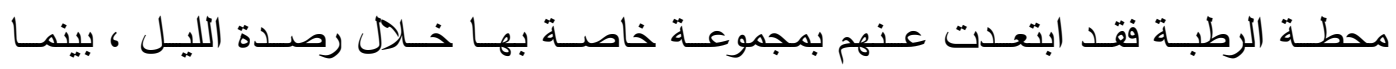

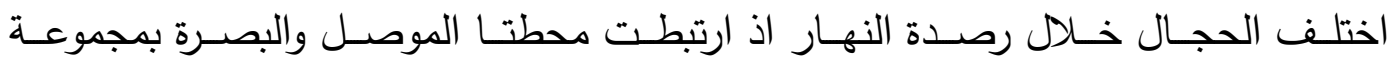

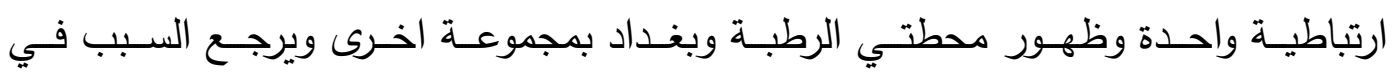
ذللك الى تباين تكرار انواع الغيوم في كل من محطات منطقة الدراسة . 
شكل ( §) المجاميع الارتباطية (العنقدة) لمعدل الحرارة المصاحبة لأيام التغييم من عدمها في

\section{المحطات المدروسة المعارة}

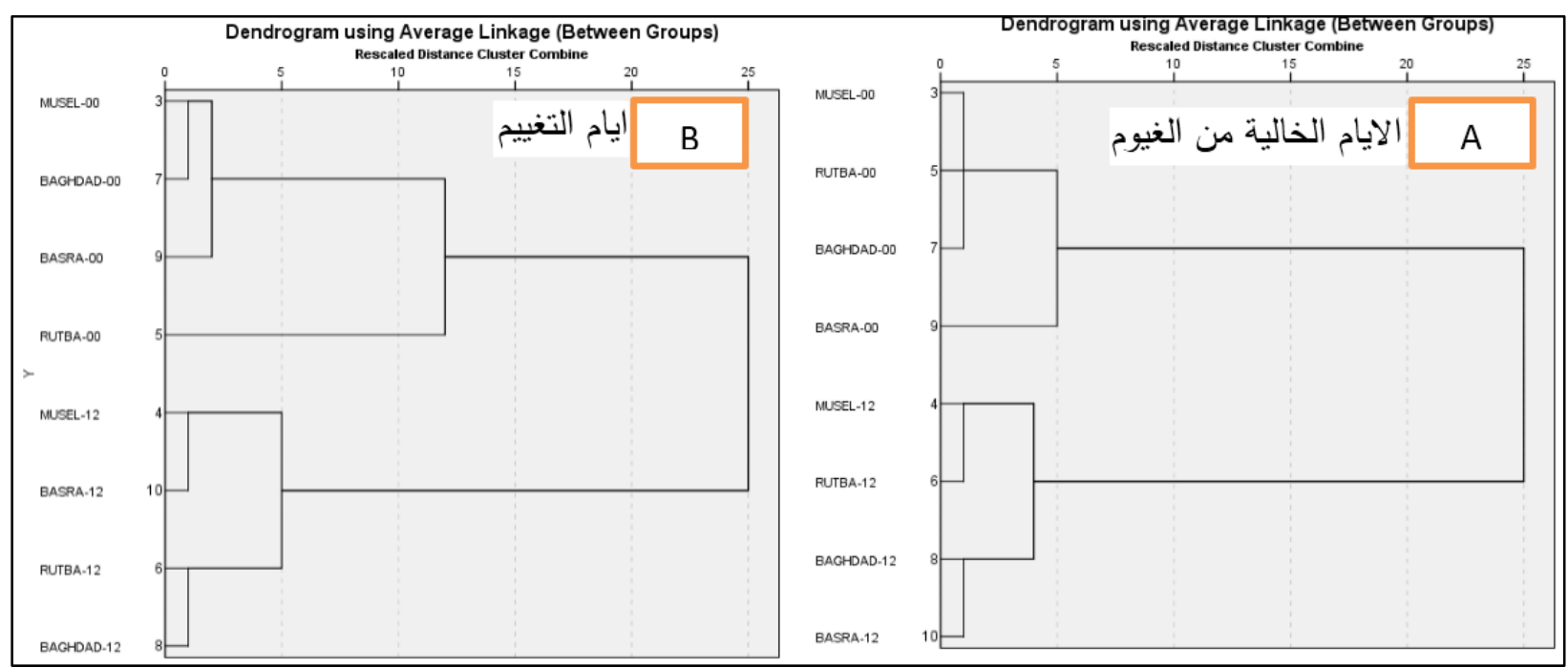

المصدر : الجدول (o)

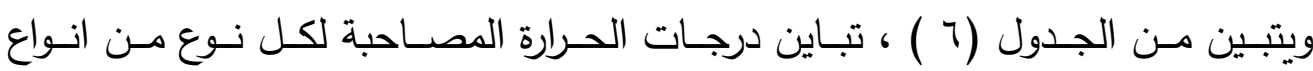

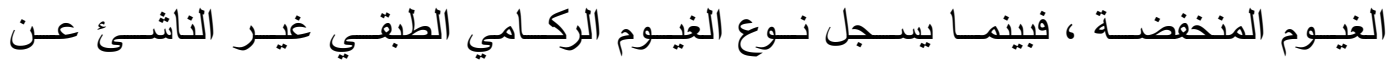

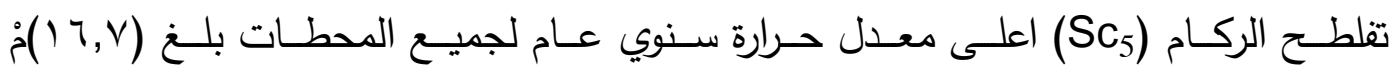

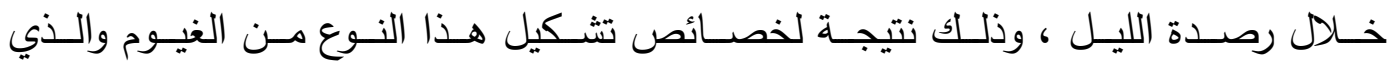

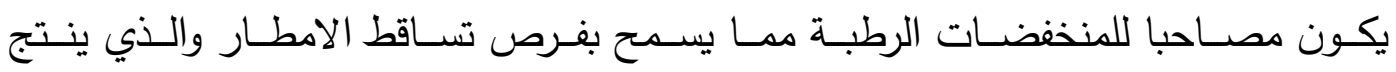

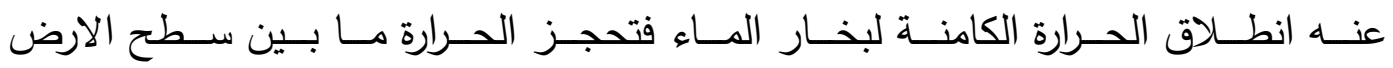

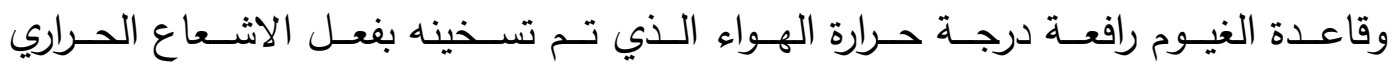

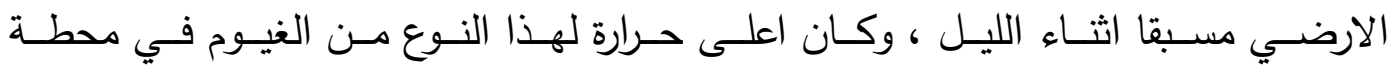

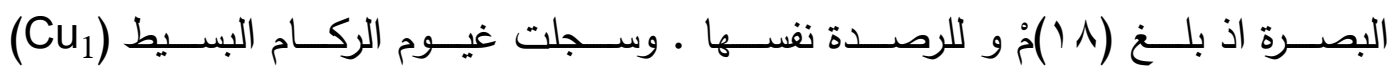

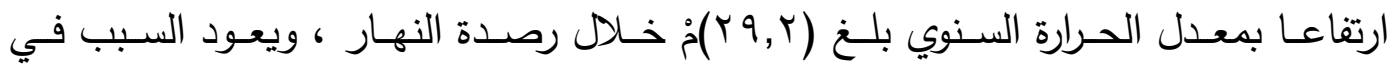

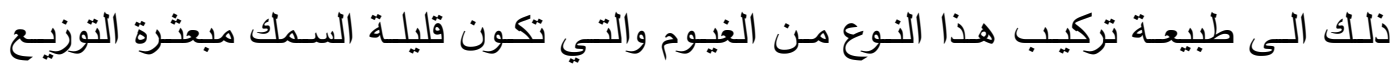

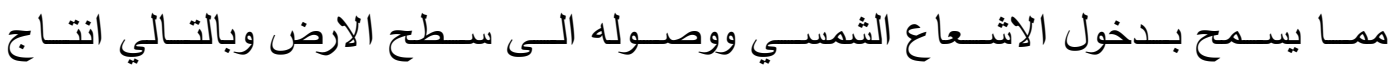

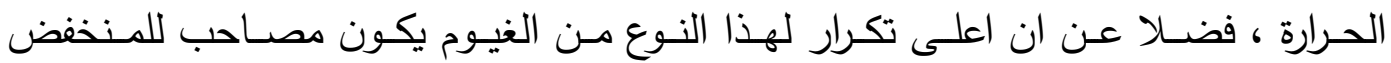

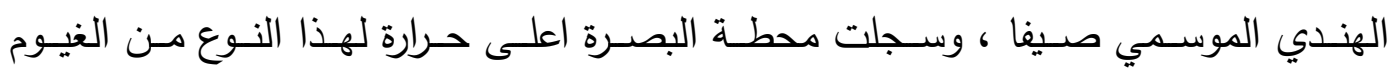

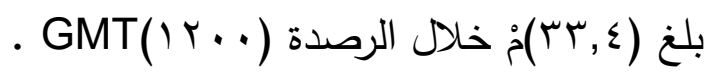




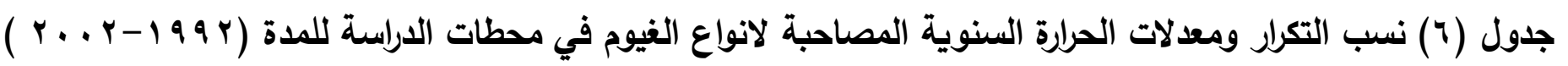

\begin{tabular}{|c|c|c|c|c|c|c|c|c|c|c|c|}
\hline \multicolumn{2}{|c|}{ معدل الحرارة العام للنوع } & \multicolumn{2}{|c|}{ البصرة } & \multicolumn{2}{|c|}{ بغداد } & \multicolumn{2}{|c|}{ الرطبة } & \multicolumn{2}{|c|}{ الموصل } & الرصدة & \multirow{2}{*}{ الغيو } \\
\hline GMT 12 & GMT 00 & GMT 12 & GMT 00 & GMT 12 & GMT 00 & GMT 12 & GMT 00 & GMT 12 & GMT 00 & المحطات & \\
\hline \multirow[b]{2}{*}{29.2} & \multirow[b]{2}{*}{16.1} & 20.1 & 40.5 & 23.3 & 19.6 & 23.9 & 10.98 & 32.7 & 28.9 & تكرار \% & \multirow[b]{2}{*}{$\mathrm{cu}_{1}$} \\
\hline & & 33.4 & 21 & 29.9 & 15 & 26.3 & 12.3 & 27.1 & 16.1 & حرارة & \\
\hline \multirow[b]{2}{*}{27.8} & \multirow[b]{2}{*}{14.6} & 16.5 & 31.3 & 19.9 & 28.9 & 27.2 & 18.1 & 36.3 & 21.7 & تكرار \% & \multirow[b]{2}{*}{$\mathrm{cu}_{2}$} \\
\hline & & 32.7 & 19 & 26.2 & 15 & 26.1 & 9.1 & 26.2 & 15.2 & حرارة & \\
\hline \multirow[b]{2}{*}{14.9} & \multirow[b]{2}{*}{8.3} & 14.1 & 75 & 11.8 & - & 30.6 & 8.3 & 43.5 & 16.7 & تكرار \% & \multirow{2}{*}{$\mathrm{cb}_{3}$} \\
\hline & & 16.9 & 13.4 & 13.3 & - & 13.8 & 6.5 & 15.5 & 5.1 & حرارة & \\
\hline \multirow[b]{2}{*}{14.2} & \multirow[b]{2}{*}{8.97} & 11.8 & 15.8 & 11.8 & 15.8 & 2.9 & 5.3 & 73.5 & 63.1 & تكرار \% & \multirow[b]{2}{*}{$\mathrm{sc}_{4}$} \\
\hline & & 13 & 8.8 & 9.5 & 8.1 & 11.1 & 9.1 & 24.1 & 9.9 & حرارة & \\
\hline \multirow[b]{2}{*}{22.8} & \multirow[b]{2}{*}{16.7} & 20.9 & 15.5 & 17.4 & 17.4 & 33.3 & 30.2 & 28.3 & 36.8 & تكرار \% & \multirow[b]{2}{*}{$\mathrm{sc}_{5}$} \\
\hline & & 23.5 & 18 & 20.97 & 17.5 & 25.2 & 13.8 & 21.7 & 17.3 & حر ارة & \\
\hline \multirow[b]{2}{*}{9.3} & \multirow[b]{2}{*}{8.9} & 46.7 & 20.6 & 11.6 & 9.5 & 16.7 & 30.2 & 25 & 39.7 & تكرار \% & \multirow[b]{2}{*}{$\mathrm{st}_{6}$} \\
\hline & & 14.6 & 10.6 & 9.2 & 10.6 & 7.3 & 4.5 & 5.97 & 9.9 & حرارة & \\
\hline \multirow[b]{2}{*}{8.2} & \multirow[b]{2}{*}{5.9} & 20.3 & 18.8 & 18.8 & - & 5.8 & 3.1 & 55.1 & 78.1 & تكرار \% & \multirow[b]{2}{*}{$\mathrm{fs}_{7}$} \\
\hline & & 10.6 & 11.1 & 11.3 & - & 3.8 & 0.8 & 6.97 & 5.8 & حرارة & \\
\hline \multirow[b]{2}{*}{24.3} & \multirow[b]{2}{*}{15.7} & 17.8 & 19.8 & 22.6 & 39.5 & 31.9 & 24.1 & 27.7 & 16.6 & تكرار \% & \multirow[b]{2}{*}{$\mathrm{sc}_{8}$} \\
\hline & & 27.5 & 20.3 & 22.1 & 15.1 & 25.8 & 12.1 & 21.7 & 15.2 & حر ارة & \\
\hline \multirow[b]{2}{*}{18.7} & \multirow[b]{2}{*}{14.4} & 9.6 & 18.6 & 22.9 & 33.3 & 13.9 & 14.7 & 53.6 & 33.3 & تكرار \% & \multirow[b]{2}{*}{$\mathrm{cb}_{9}$} \\
\hline & & 19.2 & 17.5 & 17 & 14 & 17.2 & 13.5 & 21.3 & 12.5 & حرارة & \\
\hline
\end{tabular}

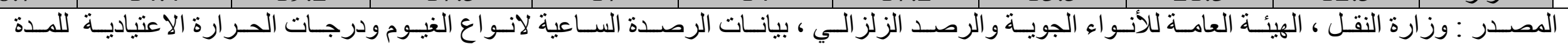




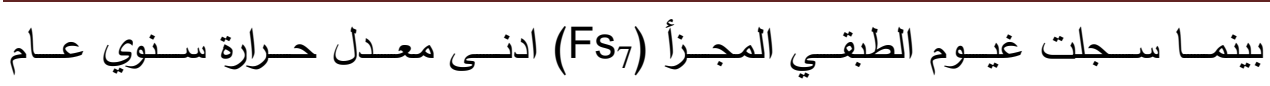

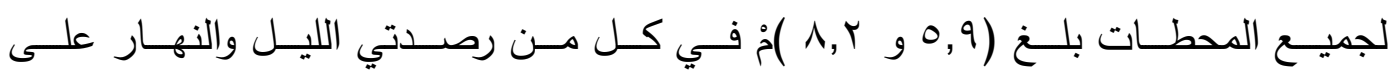

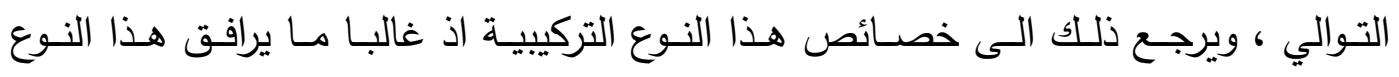

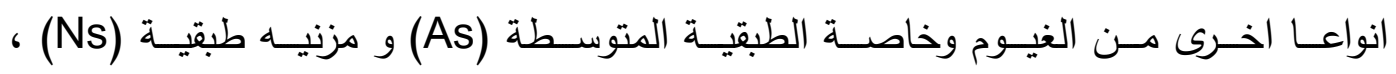

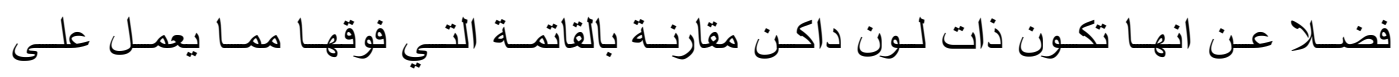

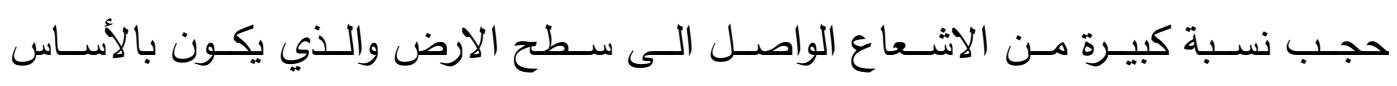

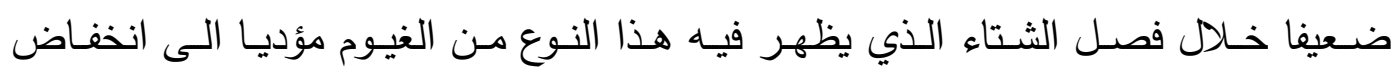

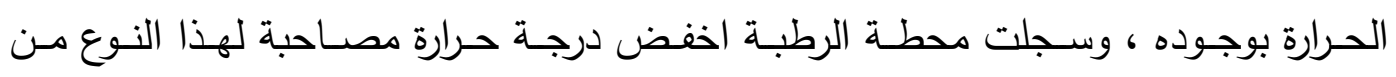

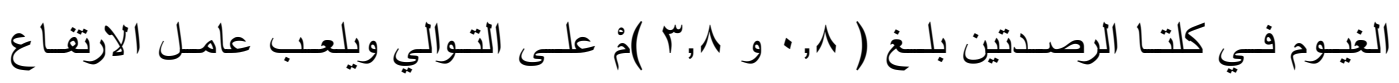

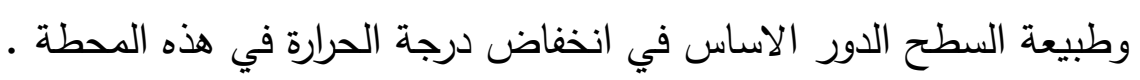

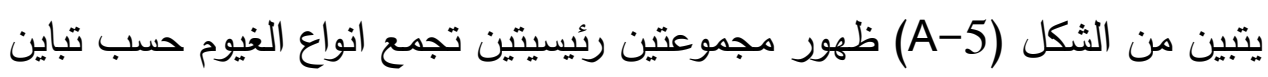

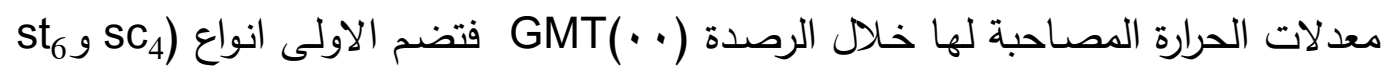

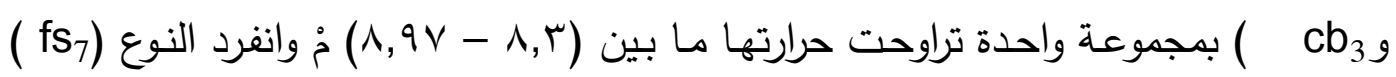

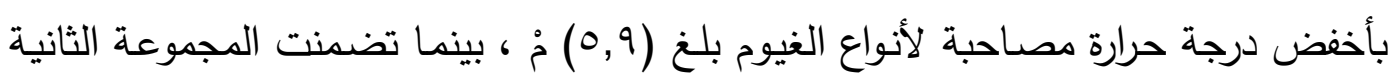

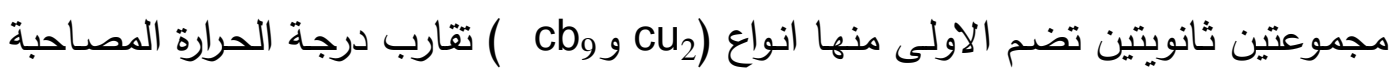

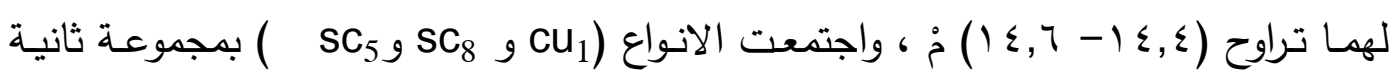

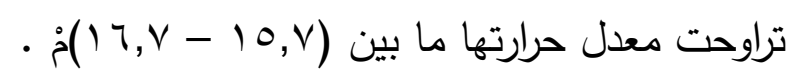

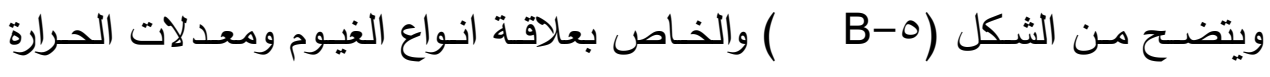

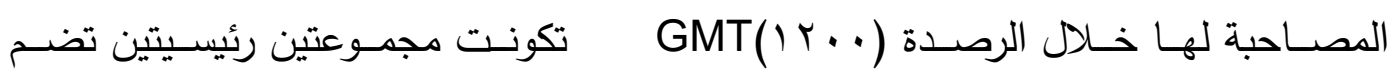

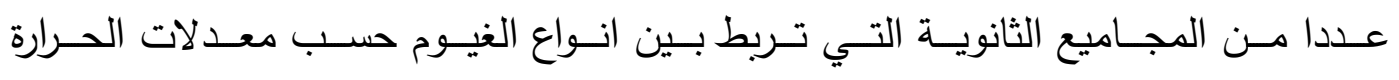

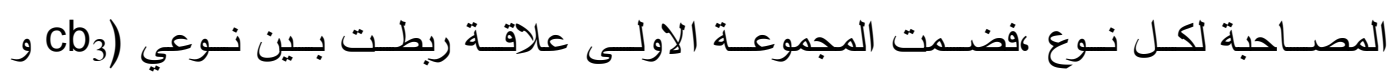

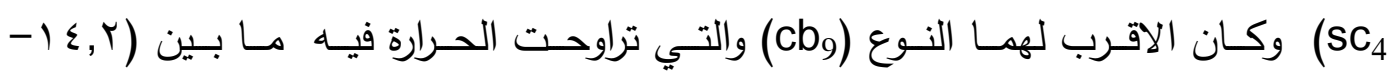

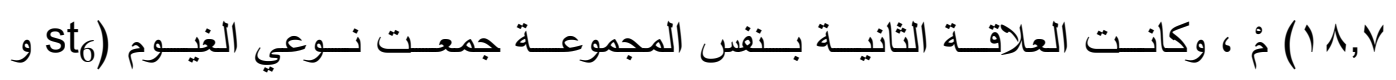
(fs

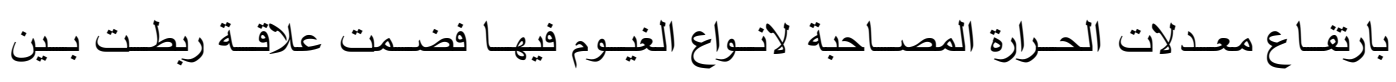

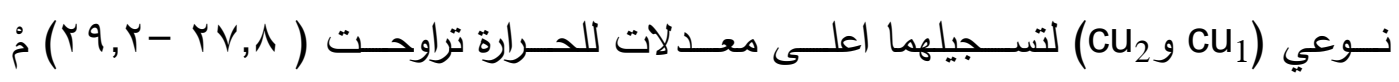

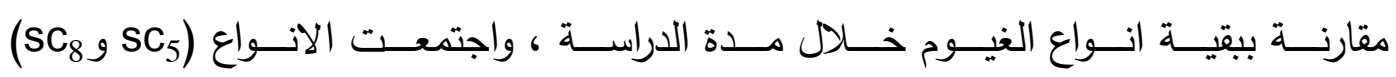

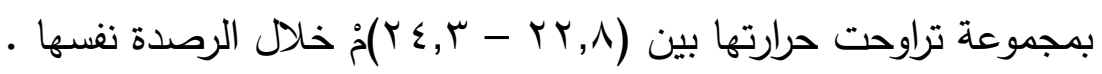


شكل (•) المجاميع الارتباطية (العنقدة) لمعدل الحرارة المصاحبة لأنواع الغيوم في

المحطات المدروسة المعذة المعلة

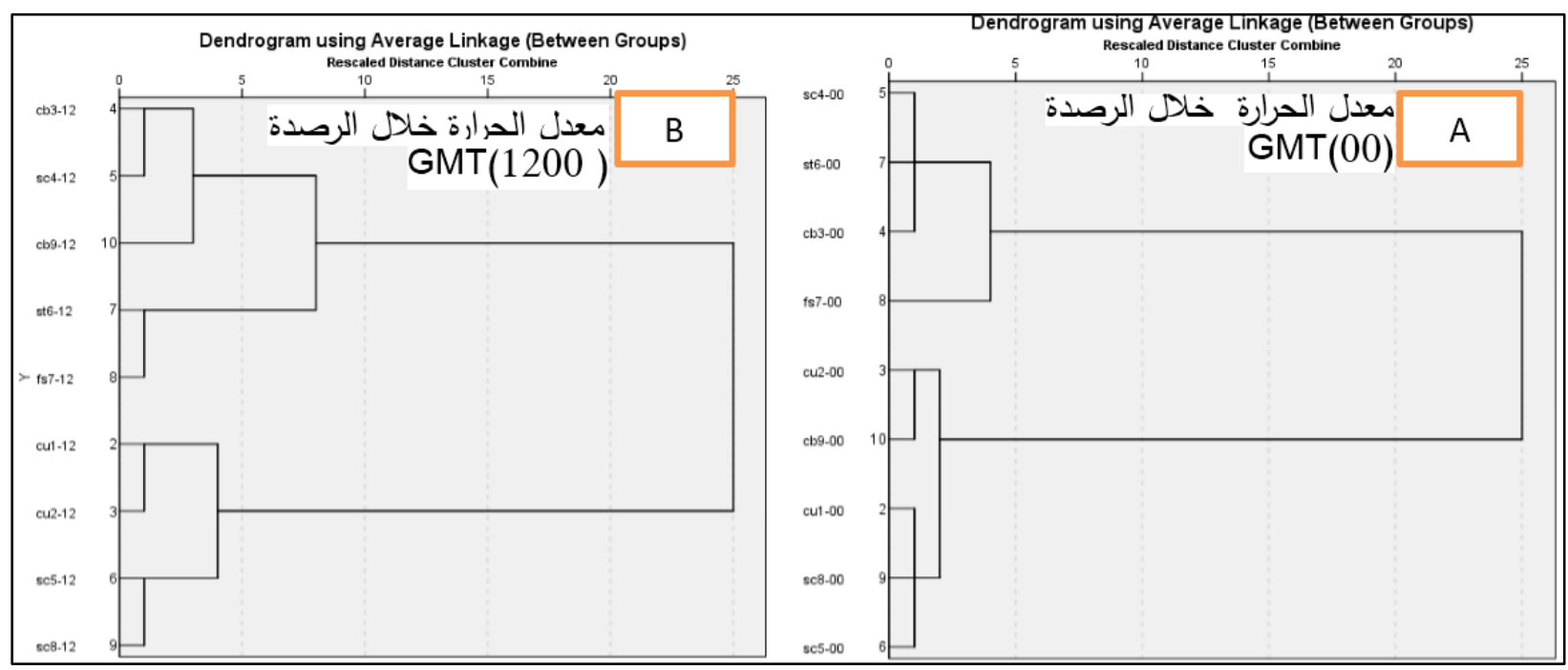

المصدر : الجدول (7)

نتائج البحث :

توصل البحث الى مجموعة من الاستتناجات هي :

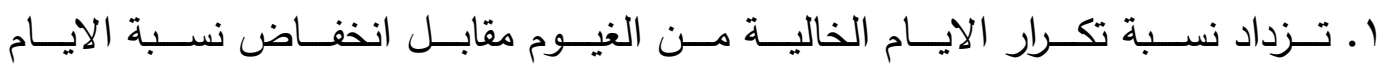

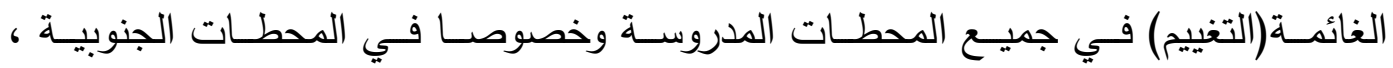

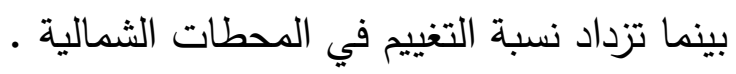

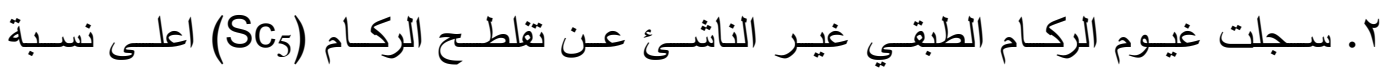

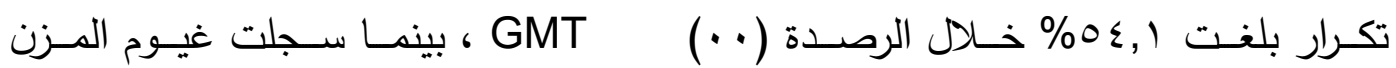

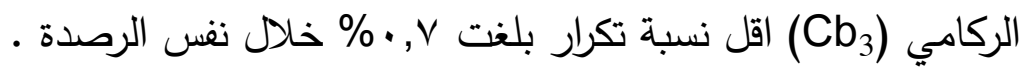

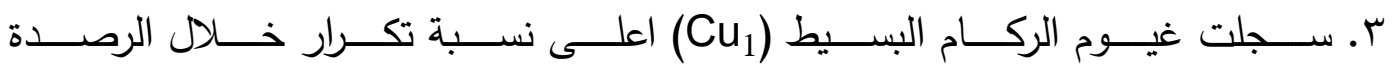

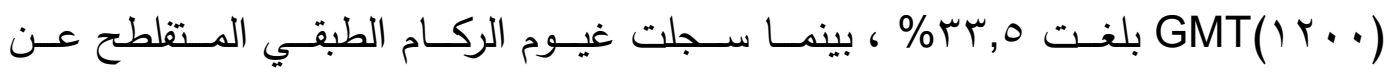

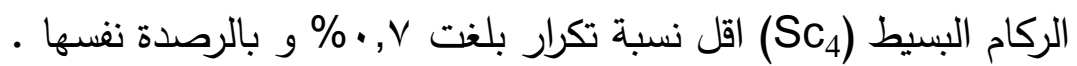

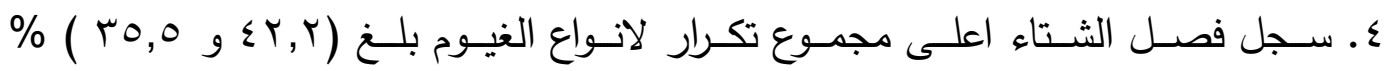

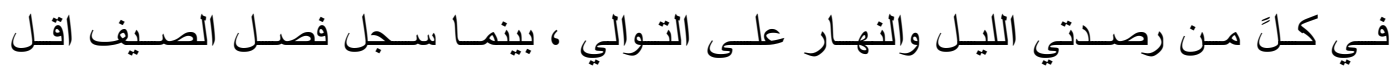

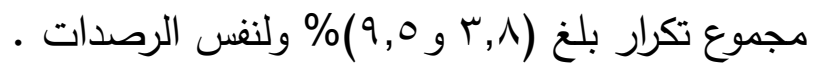
هـ تـنخفض درجـات الحرارة المصـاحبة لأيـام التغيـيم مقارنــة بالايـام الخاليـة مـن التغيـيم

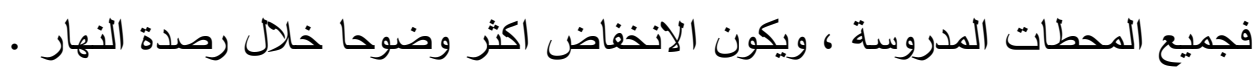

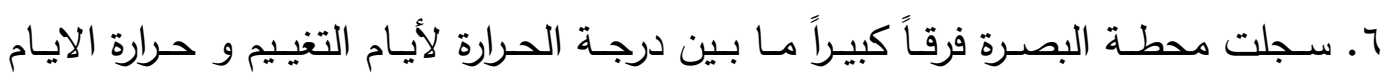

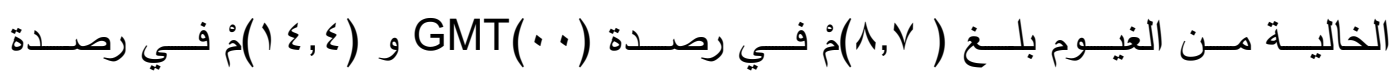
.GMT( I Y...) 
V. تتبـاين درجـات الحــرارة المصــاحبة لأنــواع الغيـوم المنخفضــة ، فســل نـوع الغيـوم (CS5)

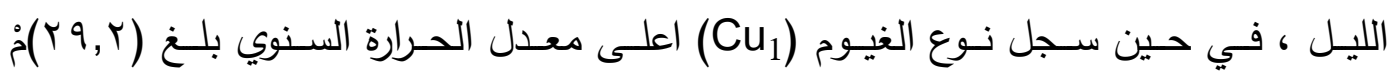

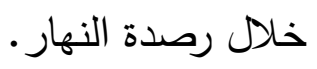

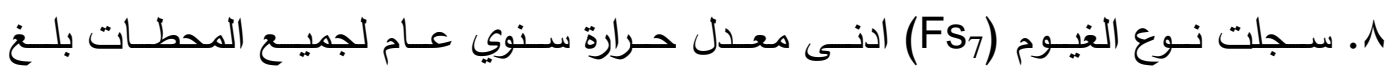

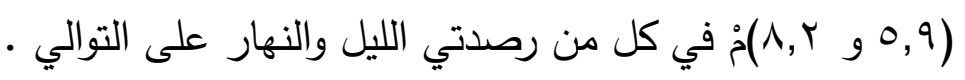
المصادر :

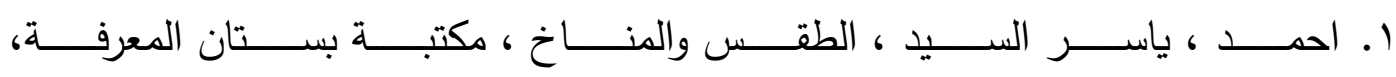

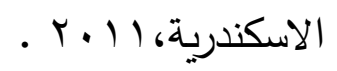

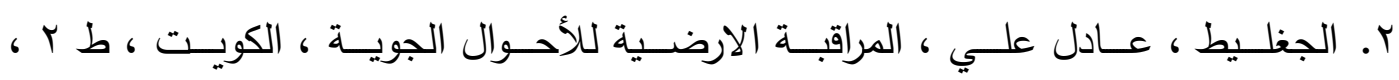
$.19 \wedge \varepsilon$

ب. الجيزانـي ، بلسـم شـاكر شنيشـل ، الاتجاهـات العامـة لتكـرار الكتـل الهوائيـة المـؤثرة في منــاخ العـراق ، اطروحسة دكتـوراه (غيـر منشـورة) ، كليـة التربيـة للبنـات ،جامعـة

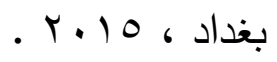

ع. السـامرائي ، قصـي عبــــ المجيــد ، مبـادئ الطقـس والمنــاخ ، دار اليـازوري للنشـر

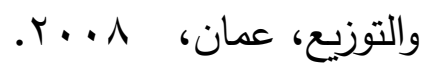

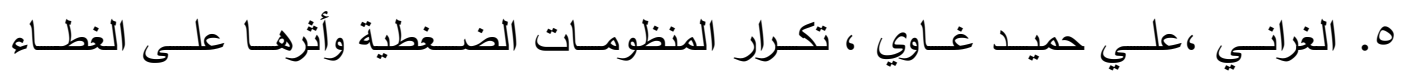
الغيمــي فـي العـراق ، رســالة ماجسـتير (غيــر منشــورة) ، كليــة التربيــة للعلــوم

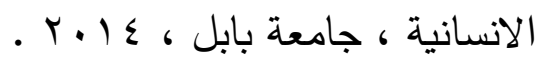

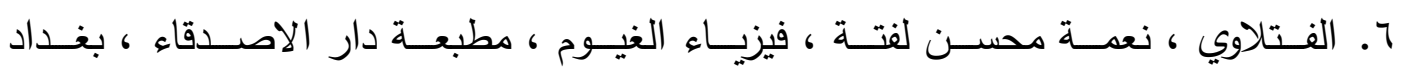
. Y...V6

V. جمهوريـة العـراق ، مجلـس الـوزراء ، هيئـة التخطـيط ، الجهـاز المركـزي للإحصــاء

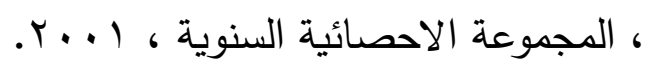

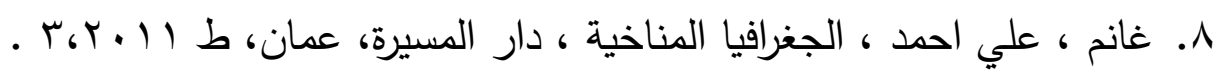
9 9. موسـى ،علي حسـن ، السـحب (الغيـوم) ، موسـوعة العلـم والحيـاة ، الطبعـة الاولـى

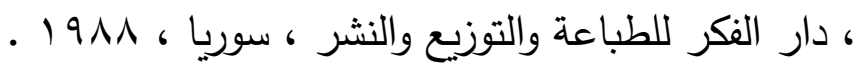

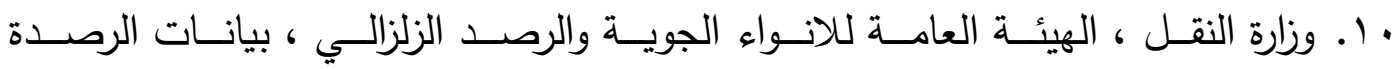

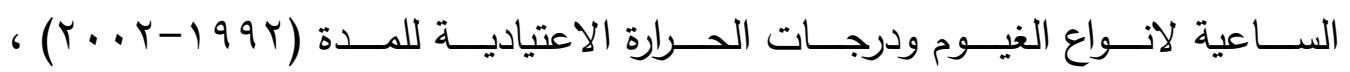
بيانات غير منشورة . 


\section{Sources:}

1. Ahmed, Yasser El Sayed, Weather and Climate, Bostan Knowledge Library, Alexandria, 2011.

2. Geography, Adel Ali, Earth Observation of Weather, Kuwait, I 2, 1984.

3. Gizani, Balsam Shaker Schnichl, general trends of the repetition of air masses affecting the climate of Iraq, doctoral dissertation (unpublished), College of Education for Girls, University of Baghdad, 2015.

4. Al-Sameraae, Qusay Abdul Majeed, Principles of Weather and Climate, Dar Al-Yazuri for Publishing and Distribution, Amman, 2008.

5. Al-Gharani, Ali Hamid Ghawi, The Repeating of Compressive Systems and their Impact on the Glimpse in Iraq, Master Thesis (unpublished), Faculty of Education for Human Sciences, Babel University, 2014.

6. Al-Fatlawi, Ne'ma Mohsen Lefta, Physics of Clouds, Dar alAsdeqaa Press, Baghdad, 2007.

7. Republic of Iraq, Council of Ministers, Planning Authority, Central Statistical Organization, Annual Statistical Group, 2001.

8. Ghanim, Ali Ahmed, Geography of Climate, Dar AlMasirah, Amman, I 3, 2011.

9. Musa, Ali Hassan, Clouds, Encyclopedia of Science and Life, First Edition, Dar al-Fikr for Printing, Distribution and Publishing, Syria, 1988.

10. Ministry of Transport, General Organization for Aeronautical and Seismic Monitoring, Observations of Clouds and Normal Temperature for the Period (1992-2002), unpublished data 


\section{Impact of cloud cover in temperatures in Iraq}

\section{Dr . Balsam Shaker Shnishal \\ Iraqi University - Faculty of Arts \\ Dr.BalsamSH85@gmail.com}

\section{Abstract:}

The current research idea was to determine the effect of the low-altitude cloud cover at a height of less than 2500 meters from the surface of the earth at normal temperature variations during the observations (00) and (1200) GMT and compare them with the temperature of the cloudless days. Repeat the nine low clouds and determine their temporal percentages during the period (1992-2002) and selectively select four climate monitoring stations distributed geographically in a manner covering all parts of Iraq.

Statistical model (The correlation of the Hirraceae) was applied to emphasis this relationship, So It appeared that there's a strong relationship between the effect of the cloud presence or not on temperature rates that connected between (Ar-Rutbah and Al-Basra) stations during the observation (00)GMT. While (Baghdad and Al-Basra) stations were connected during the observation (1200)GMT. While (summer and autumn) were connected by repetition of the same kind of clouds in them and enjoyed both (winter and spring) with a group of its own far from other seasons in each of day and night monitoring. 